NBER WORKING PAPER SERIES

\title{
THE IMPACT OF BEQUEST MOTIVES ON RETIREMENT BEHAVIOR IN JAPAN: A THEORETICAL AND EMPIRICAL ANALYSIS
}

\author{
Charles Yuji Horioka \\ Emin Gahramanov \\ Aziz Hayat \\ Xueli Tang \\ Working Paper 26621 \\ http://www.nber.org/papers/w26621 \\ NATIONAL BUREAU OF ECONOMIC RESEARCH \\ 1050 Massachusetts Avenue \\ Cambridge, MA 02138 \\ January 2020
}

The empirical work undertaken in this paper utilizes micro data from the Preference Parameters Study of Osaka University's 21st Century Center of Excellence (COE) Program "Behavioral Macrodynamics Based on Surveys and Experiments" and its Global COE Project "Human Behavior and Socioeconomic Dynamics." We acknowledge the program/project's contributors Yoshiro Tsutsui, Fumio Ohtake, and Shinsuke Ikeda. We are also grateful to Young Jun Chun, Shoshana Grossbard, Nobuaki Hamaguchi, Tetsushi Homma, Shinichiro Iwata, Young Lee, Colin McKenzie, Oleksandr Movshuk, Jan Ondrich, Steven Stern, Midori Wakabayashi, other participants at the Annual Meeting of the Society of Economics of the Household, the Family Economics Workshop in Kyoto, the Kobe University-Nanyang Technological UniversityHanyang University Joint Symposium in Economics, and seminars at ADA University (Azerbaijan), the American University of Sharjah, the Bank of France and l'Ecole des Hautes Etudes en Sciences Sociales, Monash University, Toyama University, the University of Western Australia, and especially Clémence Berson, Soungman Kang, Yoko Niimi, and Keunkwan Ryu for their valuable comments and discussions. This work was supported by a grant to Hayat from the faculty research scheme (FRGS), Department of Finance, Deakin University (2018-19) and JSPS (Japan Society for the Promotion of Science) KAKENHI Grant Numbers $15 \mathrm{H01950}$ and $18 \mathrm{H} 00870$ and a project grant from the Asian Growth Research Institute to Horioka. The views expressed herein are those of the authors and do not necessarily reflect the views of the National Bureau of Economic Research.

NBER working papers are circulated for discussion and comment purposes. They have not been peer-reviewed or been subject to the review by the NBER Board of Directors that accompanies official NBER publications.

(C) 2020 by Charles Yuji Horioka, Emin Gahramanov, Aziz Hayat, and Xueli Tang. All rights reserved. Short sections of text, not to exceed two paragraphs, may be quoted without explicit permission provided that full credit, including $\odot$ notice, is given to the source. 
The Impact of Bequest Motives on Retirement Behavior in Japan: A Theoretical and Empirical Analysis

Charles Yuji Horioka, Emin Gahramanov, Aziz Hayat, and Xueli Tang

NBER Working Paper No. 26621

January 2020

JEL No. D15,D64,J14,J22,J26

\begin{abstract}
In this paper, we conduct a theoretical and empirical analysis of the impact of bequest motives on the work and retirement behavior of households in Japan using micro data from the Preference Parameters Study of Osaka University. Our empirical findings are consistent with our theoretical model and show that respondents with an altruistic or strategic/exchange bequest motive work more at the intensive margin than those without any bequest motive but that respondents with a strategic or exchange bequest motive work less at the extensive margin (i.e., retire earlier) than those without any bequest motive. Our findings for the strategic or exchange motive suggest that respondents with such a motive tend to work harder than others before they retire so that they can earn more, leave a larger bequest to their children, and elicit more care from them but that they tend to retire earlier than others so that they can start receiving care for themselves and their spouses from their children sooner. A policy implication of our findings is that the exchange of bequests for the care of parents by children may be very sensitive to the inheritance tax framework.

Charles Yuji Horioka

Research Institute for Economics

and Business Administration

Kobe University

2-1, Rokkodai, Nada

Kobe 657-8501

JAPAN

and NBER

horioka@rieb.kobe-u.ac.jp

Emin Gahramanov

American University of Sharjah

Department of Economics

P.O. BOX 26666, Sharjah

United Arab Emirates

egahramanov@aus.edu

\author{
Aziz Hayat \\ Deakin University \\ Burwood, VIctoria 3125 \\ Australia \\ abdul.hayatmuhammad@deakin.edu.au \\ Xueli Tang \\ Deakin University \\ Department of Economics \\ Burwood, Victoria 3125 \\ Australia \\ xueli.tang@deakin.edu.au
}

Deakin Business School
\end{abstract}




\section{Introduction}

Parents and children are connected in various ways, and one of the most important ways in which they are connected is through intergenerational transfers (i.e., bequests and inter vivos transfers) from parents to children. The desire to leave bequests and other intergenerational transfers to one's children is likely to affect the economic behavior of parents in many ways. In other words, it is quite possible that parents planning to leave a bequest to their children will behave very differently from those not planning to leave a bequest to their children. For example, it is quite possible that parents planning to leave a bequest to their children will save more than those not planning to leave a bequest to their children because they need to save not only to finance their own retirement needs but also to leave a bequest to their children. Indeed, many previous studies have examined the impact of bequest motives on saving and wealth accumulation behavior, and most of them have found that parents planning to leave a bequest to their children do, in fact, save more than those not planning to leave a bequest to their children (see, for example, Horioka et al. (1996), Horioka et al. (2002), and Niimi and Horioka (2018); see Hurd (1990) for a comprehensive survey).

By the same token, it is quite possible that parents planning to leave a bequest to their children will work more at the intensive margin (i.e., work more hours per day and/or more days per year) and/or at the extensive margin (i.e., work longer and retire later) than those not planning to leave a bequest to their children so that they can increase their lifetime incomes and thence the amount that they can bequeath to their children. Moreover, work-related outcomes at both the intensive and extensive margins may differ by the nature of bequest motives (for example, by whether they are motivated by altruistic or strategic/exchange considerations). Surprisingly, however, no research has been done on the bequest-work relationship of parents that differentiates between those with different bequest motives. This paper intends to fill this gap in the literature.

The impact of bequest motives on the work-related outcomes of parents may be especially pronounced in the case of Japan where bequest motives are relatively strong. As Table 2 shows, 34.0 percent of respondents have a strong bequest motive, 47.3 percent have a weak bequest motive, and only 18.7 percent have no bequest motive at all. ${ }^{1}$ Moreover, the social norm in Japan has traditionally been for children (especially the eldest son) to provide care to elderly parents, and until a public long-term care insurance program was introduced in 2000, the elderly in Japan had to rely on their children to provide care or to pay the full cost of hiring professional care workers. Furthermore, even today, the financial burden of elderly care falls largely upon the elderly themselves because the public long-term care insurance system has a co-payment of 10 percent or more and also has strict eligibility requirements, as a result of which only care services that are concomitant with one's care needs are covered by insurance. Thus, it seems likely that a substantial proportion of Japanese has an interest in inducing their children to provide care during old age and in using bequests for this purpose (see Horioka, et al. (2018) for corroboration of this point).

In this paper, we conduct a theoretical and empirical analysis of the impact of bequest motives on the work and planned retirement decisions of households in Japan. We first do a theoretical analysis of the impact of altruistic and exchange bequest motives on work-related outcomes at

\footnotetext{
${ }^{1}$ However, Horioka (2014) finds that bequest motives are even stronger in India and the United States than in Japan although they are of roughly comparable strength in China and Japan. Thus, if we find bequest motives to have a significant impact on work-related outcomes in Japan, their impact is likely to be even greater in India and the US, where bequest motives are even stronger..
} 
the intensive and extensive margins. We then test our theoretical model's predictions empirically using micro data from the Preference Parameters Study (Kurashi no Konomi to Manzokudo ni tsuite no Chousa) of Osaka University. Consistent with our theoretical model's predictions, we find that respondents with an altruistic or strategic/exchange bequest motive work more (empirically measured by individual's working hours per week) at the intensive margin than those without any bequest motive but that respondents with a strategic or exchange bequest motive work less at the extensive margin (i.e., retire earlier, empirically measured by planned/desired retirement age) than those without any bequest motive. Our findings for the strategic or exchange bequest motive are entirely plausible because respondents with such a motive may want to work harder than others before they retire so that they can earn more, leave a larger bequest to their children, and elicit more care from them but that they may want to retire earlier than others so that they can start receiving care from their children sooner.

Moreover, our findings suggest that the altruistic bequest-work relationship in Japan is driven by relatively young respondents (those aged less than 40 years), which suggests that altruistic respondents decide their work behavior at a relatively young age. Interestingly, the strategic or exchange bequest-work relationship is driven primarily by the married male sample. A possible explanation for this finding is that married males have a greater demand for care from their children because they as well as their wives are potential care recipients.

We employ a battery of robustness checks to show that our empirical findings concerning the bequest-work relationship are highly robust, remaining significant and consistent with the predictions of our theoretical model even when (i) we use a dummy variable for full-time work in lieu of the number of hours worked per week as an alternative measure of the intensive margin, (ii) we include a large number of control variables relating to individual- and household-specific factors to ensure that the bequest-work relationship is free from the endogeneity bias arising from omitted variable(s), (iii) we ensure that our results are free from reverse relationship bias, and (iv) we add a number of proxies for wealth to eliminate the possibility that bequest motives are merely acting as a proxy for wealth, as we discuss in more detail in section 3 .

We make an original contribution to the literature in at least four respects. First, it is one of the first papers to conduct a theoretical and empirical analysis of the impact of bequest motives on the work and retirement behavior of parents at both the intensive and extensive margins. Many studies have analyzed the impact of time and monetary transfers from parents on the recipients' (children's) work behavior (see, for example, Holtz-Eakin et al. (1993), Joulfaian and Wilhelm (1994), Wolff (2006), Dustman et al. (2009), Gong (2009), Brown et al. (2010), Dimova and Wolff (2011), Elinder et al. (2012), Blau and Goodstein (2016), and Doorley and Pestel (2016) for studies for other countries and Sugano and Matsuyama (2017) and Niizeki and Hori (2019) for studies for Japan), and most of these studies find that the receipt of bequests and inter vivos transfers reduces the work behavior (the workforce participation, the number of hours worked, and the retirement age) of recipients (the so-called "Carnegie conjecture"). However, we have not been able to find any papers that analyze the impact of bequest motives on the work behavior of bequest givers (parents). The only related paper of which we are aware is Brown et al. (2015), which finds that Croatian retirees are more likely to opt for a larger but deferred stream of pension benefits if they have a stronger bequest motive. To the extent that those who choose to defer are more likely to continue working, this result implies that bequest motives have an impact on retirement behavior. Second, to the best of our knowledge, this paper is the first to conduct an analysis of the impact of bequest motives on work and retirement behavior for the case of Japan. Third, this paper uses micro data from the Preference Parameters Study, 
which reports an exhaustive list of bequest motives along with respondent's detailed attributes, such as wage, family income, full-time vs part-time, number of hours worked per week, and planned retirement age, pension, etc. Fourth, this paper distinguishes between different bequest motives (e.g., altruistic, strategic/exchange motives, etc.), as discussed in more detail later.

Our findings have important policy implications for policymakers in Japan. Since individual work behavior can be altered by changing inheritance taxes, it is very important for policymakers to realize that the bequest-work relationship exists but that it varies by bequest motive in Japan. In the case of a strategic or exchange bequest motive, which affects parents' work behavior as well as retirement decision, inheritance tax policy should be set taking account both the increased work effort at the intensive margin as well as the induced retirement effect of this motive. In the case of the altruistic bequest motive, by contrast, there does not seem to be any need to worry about the induced retirement effect, meaning that lowering inheritance taxes will unambiguously increase labor supply by encouraging individuals to leave bequests.

The remainder of this paper is organized as follows: section 2 presents the theoretical model of the impact of bequest motives on work and retirement behavior, section 3 provides empirical evidence by using micro data from the Preference Parameters Study of Osaka University to test the predictions of our theoretical model about the impact of bequest motives on work behavior (e.g., employment status, working hours, and planned retirement age), and section 4 is a concluding section.

\section{The Theoretical Model}

In this section, we present a theoretical model that shows the impact of bequest motives on work and retirement behavior. In subsection 2.1, we present the basic setup of the model; in subsection 2.2, we consider the case of altruistic bequest motives; in subsection 2.3, we consider the case of strategic or exchange bequest motives; and in subsection 2.4, we summarize our findings.

\subsection{Basic Setup}

Dynamic optimization models resulting in closed-form solutions to endogenous consumption, saving and labor supply are, to our knowledge, rare. They are often used in quantitative finance and related economics literature to investigate decision-making under uncertainty. For example, Rogers (2013, p. 110) augments a standard infinite-horizon Merton problem with the intensive margin of labor supply and numerically simulates the solutions. Similarly, Rogers (2013, p. 99) presents a Merton-type model with endogenous retirement and presents an explicit solution to the critical value of wealth that would trigger retirement. Farhi and Panageas (2007) endogenize risky investment with endogenous retirement choice only. This allows the authors to focus on closed-form solutions. Our model abstracts from risky investment and focuses on closed-form solutions pertinent to both margins of labor supply in the context of parentoffspring transfers. The dynamic quantitative-theoretical literature with labor supply is large. The interested reader might refer, for instance, to Bagchi's (2015) study that numerically simulates the effect of the U.S. Social Security system on different margins of labor supply in an environment with mortality and labor income risk and also cites many studies that look at dynamic pension reforms and labor supply distortions. 
Our model features a standard bounded optimal control framework in which we focus on closed-form solutions by explicitly taking into account the time constraint on leisure. Most standard theoretical studies with closed-form solutions consider an interior solution with respect to labor supply (e.g., Bütler 2001) for ease of exposition, but we follow the approach developed in Gahramanov and Tang (2016a; 2016b) for deriving the optimal age of retirement and hours worked. In addition, under various assumptions, we are able to provide analytic solutions for the optimal inheritance level.

Our model is set in continuous time, and time itself is denoted by $t$. To derive closed-form solutions, we attempt to keep the environment as simple as possible. The main decision-maker (the "agent" or "parent") enters the workforce at birth $(t=0)$ and exits the model by age $t=$ $T>0$. The time endowment is normalized to unity. The retirement age $\left(T_{\text {ret }}\right)$ must be chosen optimally. For each unit of labor endogenously devoted to market work at date $t$, exogenously determined efficiency units $(\epsilon(t))$ are supplied to production. The wage per labor efficiency unit is $w>0$. All wage income not consumed flows into the individual's financial asset account $k(t)$, which grows at rate $r$. The main decision-maker starts the life cycle with a given amount of bequest received from her own parent $\left(B^{R} \geq 0\right)$, and she finishes the life cycle with some assets $k$ (determined endogenously) that she will bequeath to her offspring at time $t=T$.

Suppose that culture and social norms help to shape the care level a person might devote to her parent (and possibly to others, such as other family members). The overall amount of care requires a sacrifice of time and is a strictly increasing function of the bequest received (see subsection 2.2 for more discussion of this.)

Remark 1. From here on in, we assume that the main decision-maker starts her life with no assets $\left(B^{R}=0\right)$, and provides no care to her own parents. This assumption is innocuous because at the start of the model, $B^{R}$ and the resulting care-to-own-parents will be exogenously given by assumption and will be mainly driven by the decisions of the parents of the main decision-maker. Setting these values to zero allows us to state our forthcoming solutions in a more compact way and to focus exclusively on the interaction between the main decision-making agent and her children.

The agent enjoys (derives utility from) private consumption $(c(t))$ and personal leisure $(l(t))$. Note that the agent's hours of work $(1-l(t))$ are endogenous since $l(t)$ is a choice variable. In what follows, we consider two separate cases - the case of an altruistic bequest motive and the case of a selfishly motivated strategic or exchange bequest motive.

\subsection{Case 1: Altruistic Bequest Motives}

When modeling the case of altruistic bequest motives, we assume that the bequest left by the parent increases her utility because it increases the present value of resources available to her child and thus by implication the child's ultimate consumption. By contrast, Wilhelm (1996), Kopczuk (2010), and especially Laitner and Ohlsson (2001) have in mind Barro-type recursive altruism models in which the parent cares about the consumption and therefore the well-being of her children, grandchildren, and more distant descendants. These models assume that the inheritance provided by the parent directly influences the consumption available to the child (see eq. 1 on p. 208 in Laitner and Ohlsson, 2001). Laitner and Ohlsson (2001, p. 210) and 
Kopczuk (2010, p. 6) differentiate our formulation from the altruism model and refer to it as the "egoistic model" or the "joy-of-giving model," and indeed the two formulations have very different implications for public policy. However, since we are not concerned about Ricardian equivalence or tax considerations, we can presume that this fine distinction in the parent's motivations is not important for our purposes and that our Case 1 corresponds in broad terms to the "altruistic bequest motive" setting. Wilhelm (2010, pp. 880-881) makes a similar argument (see also Arrondel and Masson, 2006, and Laferrere and Wolff, 2006).

The objective in our altruism model is to maximize

$$
\begin{gathered}
U=\int_{0}^{T} e^{-\rho t}\left(\phi_{1} \ln [c(t)]+\phi_{2} \ln [l(t)]\right) d t \\
+\gamma e^{-\rho T} \ln [\Psi(k(T))]
\end{gathered}
$$

where $\phi_{1}, \phi_{2}, \gamma$ are positive constants, and $\rho$ is nonnegative.

Remark 2. Let function $\Psi$ summarize the present value of economic resources available to the child over the latter's lifetime as seen from the perspective of the decision-making parent. We assume that the parent believes that if her offspring is given a larger bequest, this will increase the present value of resources available to the latter; that is, $\frac{\partial \Psi}{k(T)}>0 .^{2}$

Observe from (1) that a function of the terminal stock $k(T)$ is added to the integral, and this "scrap value function" has the standard economic interpretation (e.g., Léonard and Van Long, 1992, pp. 226-229). In other words, the parent attaches some positive value to what she leaves behind at time $T$ because she has an altruistic bequest motive.

The optimization problem is subject to the dynamic budget equation, control constraints, and the endpoint conditions given in (2)-(5):

$$
\begin{gathered}
\frac{d k(t)}{d t}=r k(t)+w \epsilon(t)(1-l(t))-c(t), \\
0 \leq l(t) \leq 1, \\
k(0)=0, \\
k(T)=\text { free. }
\end{gathered}
$$

Equation (4) is consistent with Remark 1. Note that the chosen utility function allows us to ignore the additional control constraint on $c(t)$. Further, given (5), the solution to the problem can be obtained by using a transversality condition for a free endpoint with scrap value that would essentially equate the marginal benefit of an increase in the terminal asset level to the associated marginal cost over the entire time interval. For ease of exposition, however, we proceed with the two-step procedure outlined in the remark below when deriving the solution.

Remark 3. Here we adapt the two-step solution strategy as follows: (i) solve the optimization problem treating $k(T)$ as fixed (i.e., $k(T)$ is arbitrarily fixed at some amount of $B^{G}$ or

\footnotetext{
${ }^{2}$ In principle, it is possible that a larger bequest would discourage, say, work effort and ultimately leave the child financially worse off (or no better off), but we assume that the parent rules out such a possibility when making a decision.
} 
"bequest given"), and then (ii) solve for the optimal value of $B^{G}$ given that consumption and labor supply are chosen optimally for every possible $B^{G}$ value. ${ }^{3}$

In the first step, we thus define the Hamiltonian function

$$
\begin{gathered}
H_{1}=e^{-\rho t}\left(\phi_{1} \ln [c(t)]+\phi_{2} \ln [l(t)]\right)+\mu(t)(r k(t)+w \epsilon(t)(1 \\
-l(t))-c(t)),
\end{gathered}
$$

where $\mu(t)$ is a dynamic multiplier. Optimal controls must satisfy the following conditions:

$$
\begin{gathered}
\frac{d k(t)}{d t}=\frac{\partial H_{1}}{\partial \mu(t)}=r k(t)+w \epsilon(t)(1-l(t))-c(t), \\
\frac{d \mu(t)}{d t}=-\frac{\partial H_{1}}{\partial k(t)}=-\mu(t) r
\end{gathered}
$$

and

$$
\begin{gathered}
\max _{\{1-l(t) \geq 0, c(t)\}} H_{1} \Leftrightarrow \\
\max _{\{1-l(t) \geq 0, c(t)\}}\left\{H_{2}\right. \\
=e^{-\rho t}\left(\phi_{1} \ln [c(t)]+\phi_{2} \ln [l(t)]\right) \\
+\mu(t)(w \epsilon(t)(1-l(t))-c(t))\} .
\end{gathered}
$$

A necessary condition is that there exists a dynamic multiplier $\lambda(t) \leq 0$ such that if the Lagrangian of the Hamiltonian

$$
\begin{gathered}
H=e^{-\rho t}\left(\phi_{1} \ln [c(t)]+\phi_{2} \ln [l(t)]\right)+\mu(t)(w \epsilon(t)(1-l(t)) \\
-c(t))+\lambda(t)(l(t)-1),
\end{gathered}
$$

then (11)-(14) hold:

$$
\begin{gathered}
\frac{\partial H}{\partial c(t)}=\phi_{1} e^{-\rho t} c(t)^{-1}-\mu(t)=0 \\
\frac{\partial H}{\partial l(t)}=\phi_{2} e^{-\rho t} l(t)^{-1}-\mu(t) w \epsilon(t)+\lambda(t)=0 \\
\lambda(t)(l(t)-1)=0 \\
1-l(t) \geq 0 .
\end{gathered}
$$

We focus our attention on standard labor supply behavior. Let there be some internal point in time $T_{\text {ret }} \in(0, T)$ (to be determined) on or after which the agent stops working, and hence $l(t)=1$. Thus,

$$
\begin{aligned}
& l(t)<1 \text { for } t \in\left[0, T_{\text {ret }}\right), \\
& l(t)=1 \text { for } t \in\left[T_{\text {ret }}, T\right] .
\end{aligned}
$$

\footnotetext{
${ }^{3}$ Furthermore, since the solution to such dynamic problems can still easily become cumbersome, we will assume that the discount rate and the interest rate are equal in order to facilitate the analysis.
} 
The complementarity condition implies that if $\lambda(t)=0$, then $l(t)<1$, and we have the following system of equations:

$$
\left(\begin{array}{l}
k(t) \\
\mu(t)
\end{array}\right)^{\prime}=\left(\begin{array}{c}
r k(t)+w \epsilon(t)(1-l(t))-c(t) \\
-\mu(t) r
\end{array}\right)
$$

for $t \in\left[0, T_{\text {ret }}\right)$.

If, on the other hand, $\lambda(t)<0$, then $l(t)=1$, and we have the following system of equations:

$$
\left(\begin{array}{l}
k(t) \\
\mu(t)
\end{array}\right)^{\prime}=\left(\begin{array}{c}
r k(t)-c(t) \\
-\mu(t) r
\end{array}\right)
$$

for $t \in\left[T_{r e t}, T\right]$. Hence, the optimal solution can be found by joining together the solutions of (17)-(18). Note that the function $\mu(t)$ is defined over the entire planning interval, and from (17) and (18) we see that it obeys the same law of motion. Since the function is continuous, we obtain

$$
\mu(t)=a e^{-r t} \text { for } t \in[0, T],
$$

where $a$ is a constant to be determined.

From (11), we obtain

$$
c(t)=\phi_{1} e^{-\rho t} / \mu(t)
$$

Now, note that if $\lambda(t)=0$, then $l(t)<1$. Hence, (12) leads to

$$
\mu(t)=a e^{-r t}=\phi_{2} e^{-\rho t} l(t)^{-1}(1 / w \epsilon(t)) .
$$

Recall that $l\left(T_{\text {ret }}\right)=1$. Substituting this into (21) (and recalling that $r=\rho$ ), we can express the constant $a$ in terms of $T_{r e t}$ as

$$
a \equiv a\left(T_{r e t}\right)=\phi_{2} /\left(w \epsilon\left(T_{r e t}\right)\right)
$$

Thus,

$$
\mu(t)=a\left(T_{r e t}\right) e^{-r t} \text { for } t \in[0, T] .
$$

Substituting (23) into (20), we obtain from (18)

$$
\frac{d k(t)}{d t}=r k(t)-\frac{\phi_{1}}{a\left(T_{\text {ret }}\right)},
$$

for $t \in\left[T_{r e t}, T\right]$.

Using (5) for an arbitrarily fixed terminal stock value $B^{G}$, we derive the solution to (24) as 


$$
k(t)=\frac{\phi_{1}}{r a\left(T_{r e t}\right)}\left(1-e^{r(t-T)}\right)+B^{G} e^{r(t-T)},
$$

for $t \in\left[T_{r e t}, T\right]$.

Evaluating (25) at $t=T_{\text {ret }}$, we obtain

$$
\begin{aligned}
& k\left(T_{r e t}\right) \equiv \Lambda_{1}\left(T_{r e t}\right) \\
& =\frac{\phi_{1}}{r a\left(T_{r e t}\right)}\left(1-e^{r\left(T_{r e t}-T\right)}\right)+B^{G} e^{r\left(T_{r e t}-T\right)} .
\end{aligned}
$$

Next, substituting (23) into (11) and (12) and considering the $\lambda(t)=0$ case (recall that $r=$ $\rho$ ), we solve for the optimal consumption and leisure paths as functions of $T_{\text {ret }}$ :

$$
\begin{gathered}
c(t)=\frac{\phi_{1}}{a\left(T_{r e t}\right)}, \\
l(t)=\frac{\phi_{2}}{a\left(T_{r e t}\right) w \epsilon(t)},
\end{gathered}
$$

for $t \in\left[0, T_{\text {ret }}\right)$.

Remark 4. Note from (28) that for the agent to retire before exiting the model, it is necessary that the labor productivity profile, $\epsilon(t)$, decline sufficiently rapidly after some point in time.

Substituting (27) and (28) into (17), we obtain

$$
\frac{d k(t)}{d t}=r k(t)+w \epsilon(t)\left(1-\frac{\phi_{2}}{a\left(T_{r e t}\right) w \epsilon(t)}\right)-\frac{\phi_{1}}{a\left(T_{r e t}\right)}
$$

for $t \in\left[0, T_{r e t}\right)$. Using (4), the solution to (29) is

$$
\begin{gathered}
k(t)=e^{r t} \int_{0}^{t}\left(w \epsilon(u)\left(1-\frac{\phi_{2}}{a\left(T_{r e t}\right) w \epsilon(u)}\right)\right. \\
\left.-\frac{\phi_{1}}{a\left(T_{r e t}\right)}\right) e^{-r u} d u,
\end{gathered}
$$

for $t \in\left[0, T_{\text {ret }}\right)$. Expression (30) implies that

$$
\begin{aligned}
k\left(T_{\text {ret }}\right) \equiv \Lambda_{2}\left(T_{\text {ret }}\right) & \\
& =e^{r T_{\text {ret }}} \int_{0}^{T_{\text {ret }}}\left(w \epsilon(t)\left(1-\frac{\phi_{2}}{a\left(T_{\text {ret }}\right) w \epsilon(t)}\right)\right. \\
& \left.-\frac{\phi_{1}}{a\left(T_{\text {ret }}\right)}\right) e^{-r t} d t .
\end{aligned}
$$

Hence, for a given bequest amount $B^{G}$, $T_{\text {ret }}$ is the solution to the following equation:

$$
\Lambda_{1}\left(T_{r e t}\right)=\Lambda_{2}\left(T_{r e t}\right) .
$$


Remark 5. It is clear from (32) that even a simple dynamic model can easily lead to a cumbersome solution, and it might be impossible to derive a closed-form solution. To obtain a tractable, closed-form solution, we introduce additional simplifying assumptions. First, we assume that the interest rate $r=0$ (an assumption that is quite reasonable in the case of Japan). Also, we assume that $\epsilon(t)=1-(1 / T) t$.

Consequently, recalling (22), we obtain

$$
\begin{gathered}
\lim _{r \rightarrow 0} \Lambda_{1}\left(T_{r e t}\right)=B^{G}+\frac{w\left(T-T_{r e t}\right)^{2} \phi_{1}}{T \phi_{2}}, \\
\lim _{r \rightarrow 0} \Lambda_{2}\left(T_{r e t}\right)=\frac{w T_{r e t}\left(T_{r e t}\left(2 \phi_{1}+\phi_{2}\right)-2 T \phi_{1}\right)}{2 T \phi_{2}} .
\end{gathered}
$$

Thus, setting (33) equal to (34), we can solve for the optimal retirement age for a given bequest amount. Under the assumption of both roots being real, a positive root takes the form

$$
T_{\text {ret }}\left(B^{G}\right)=\frac{-T \phi_{1}+\sqrt{D} / w}{\phi_{2}},
$$

where

$$
D \equiv w T\left(2 B^{G} \phi_{2}^{2}+w T \phi_{1}\left(\phi_{1}+2 \phi_{2}\right)\right)
$$

Remark 6. It is clear from (36) that an exogenous increase in the amount of the bequest given $B^{G}$ would raise the age of retirement. However, the next task is to find the optimal bequest amount. For that purpose, we need to specify the form of the $\Psi$ function.

For the sake of simplicity, let us assume that the parent believes that a one-unit increase in the bequest given increases the lifetime well-being of her offspring by $s>0$ units, where $s$ can be sufficiently small. Let

$$
\Psi\left(B^{G}\right)=s B^{G}
$$

Recalling that $r=\rho=0$, using (22), (27)-(28), (35), and (37), let us rewrite (1) as

$$
\Gamma_{1}+\Gamma_{2}
$$

where

$$
\begin{aligned}
& \Gamma_{1} \equiv \phi_{1} \int_{0}^{T_{\text {ret }}\left(B^{G}\right)} \ln \left[\frac{\phi_{1}}{a\left(T_{\text {ret }}\left(B^{G}\right)\right)}\right] d t \\
&+\phi_{2} \int_{0}^{T_{r e t}\left(B^{G}\right)} \ln \left[\frac{\phi_{2}}{a\left(T_{r e t}\left(B^{G}\right)\right) w \epsilon(t)}\right] d t \\
&+\gamma \ln \left[s B^{G}\right], \\
& \Gamma_{2} \equiv \phi_{1} \int_{T_{r e t}\left(B^{G}\right)}^{T} \ln \left[\frac{\phi_{1}}{a\left(T_{r e t}\left(B^{G}\right)\right)}\right] d t+\phi_{2} \int_{T_{r e t}\left(B^{G}\right)}^{T} \ln [1] d t .
\end{aligned}
$$


The optimal bequest amount $B^{G}$ is the one that solves

$$
\frac{\partial \Gamma_{1}}{\partial B^{G}}+\frac{\partial \Gamma_{2}}{\partial B^{G}}=0
$$

Under the assumption of real roots, the optimal bequest amount $\left(B_{o p t}^{G}=k(T)_{\text {opt }}\right)$ is

$$
B_{o p t}^{G}=\frac{w \gamma\left(T\left(\phi_{1}+\phi_{2}\right)+\gamma-\sqrt{D_{1}}\right)}{T \phi_{2}^{2}}
$$

where

$$
D_{1} \equiv\left(T \phi_{1}+\gamma\right)\left(T \phi_{1}+2 T \phi_{2}+\gamma\right)
$$

Substituting (42) into (35), we obtain the optimal retirement age $\left(T_{\text {ret }}^{\text {opt }}\right)$ as follows:

$$
T_{\text {ret }}^{o p t}=-\frac{1}{\phi_{2}}\left(T \phi_{1}-\sqrt{D_{2}-2 \gamma \sqrt{D_{1}}}\right) .
$$

where

$$
D_{2} \equiv 2 \gamma^{2}+2 T \gamma\left(\phi_{1}+\phi_{2}\right)+T^{2} \phi_{1}\left(\phi_{1}+2 \phi_{2}\right) \text {. }
$$

Analogously, we can find the optimal leisure profile $\left(l(t)^{o p t}\right)$, and ultimately the optimal labor supply $\left(L S(t)^{o p t}\right)$ during the working life as follows:

$$
L S(t)^{o p t} \equiv 1-l(t)^{o p t}=\frac{T \phi_{1}+t \phi_{2}-\sqrt{D_{2}-2 \gamma \sqrt{D_{1}}}}{(t-T) \phi_{2}} .
$$

The optimal consumption profile takes the form

$$
c(t)^{o p t}=w \phi_{1} \frac{T\left(\phi_{1}+\phi_{2}\right)-\sqrt{D_{2}-2 \gamma \sqrt{D_{1}}}}{T \phi_{2}^{2}} .
$$

Notice that

$$
\frac{\partial B_{o p t}^{G}}{\partial \gamma}=-w \frac{\left(\sqrt{D_{1}}-\gamma-T\left(\phi_{1}+\phi_{2}\right)\right)\left(\sqrt{D_{1}}-\gamma\right)}{T \phi_{2}^{2} \sqrt{D_{1}}} .
$$

The term $\sqrt{D_{1}}$ is strictly less than $\left(\gamma+T\left(\phi_{1}+\phi_{2}\right)\right.$, while $\sqrt{D_{1}}$ is strictly greater than $\gamma$. Therefore, (48) is strictly positive in sign, indicating that the more the parent cares for her child's financial well-being, the larger the bequest she intends to leave. Similarly, 


$$
\begin{aligned}
& \frac{\partial L S(t)^{o p t}}{\partial \gamma} \\
& =\frac{4 \gamma^{2}+6 T \gamma\left(\phi_{1}+\phi_{2}\right)+2 T^{2} \phi_{1}\left(\phi_{1}+2 \phi_{2}\right)-\left(4 \gamma+2 T\left(\phi_{1}+\phi_{2}\right)\right) \sqrt{D_{1}}}{2(t-T) \phi_{2} \sqrt{D_{1}} \sqrt{D_{2}-2 \gamma \sqrt{D_{1}}}} .
\end{aligned}
$$

The denominator of (49) is negative since up to the age of retirement, $t<T$. The numerator is negative since the term $\left(4 \gamma+2 T\left(\phi_{1}+\phi_{2}\right)\right)^{2} D_{1}$ exceeds the term $\left(4 \gamma^{2}+6 T \gamma\left(\phi_{1}+\right.\right.$ $\left.\left.\phi_{2}\right)+2 T^{2} \phi_{1}\left(\phi_{1}+2 \phi_{2}\right)\right)^{2}$ by a positive amount $4 T^{3} \phi_{2}^{2}\left(2 \gamma\left(\phi_{1}+\phi_{2}\right)+T \phi_{1}\left(\phi_{1}+2 \phi_{2}\right)\right)$. Thus, an increase in the strength of the altruistic bequest motive increases the number of working hours.

Finally,

$$
\frac{\partial T_{r e t}^{o p t}}{\partial \gamma}=\frac{\partial L S(t)^{o p t}}{\partial \gamma}(T-t)
$$

Since (49) is positive, so is (50), implying that an increase in the strength of the altruistic bequest motive delays retirement. Thus, we conclude with

Remark 7. An increase in the strength of the altruistic bequest motive will cause parents to not only work more hours per week but also to work longer and retire later, as shown by equations (49) and (50).

\subsection{Case 2: Strategic or Exchange Bequest Motives}

In this subsection, we assume that parents leave a bequest to elicit care and/or attention from their children. This is the so-called strategic or exchange bequest motive discussed by Laitner and Ohlsson (2001, p. 211) and Bernheim, Shleifer, and Summers (1985). Some questions arise immediately. Suppose a child took good care of her elderly parents by sacrificing time and resources. How can he/she be sure that her parents will reward him or her properly and will not renege on their implicit or explicit promise? By contrast, even if parents gave the promised reward to their child, the latter might still fail to carry out her duties as promised. After all, if intra-household gifts and exchanges are based on purely selfish motives to begin with, selfish individuals might consider breaking their promises whenever they felt like it.

Real life is more complex, however. Even if it is in an individual's self-interest to break an agreement, often a society develops social customs and rules to minimize such deviant behavior, and such social customs might be easier to enforce between members of one family (who tend to be bound by intra-household trust and affection) than between total strangers. Moreover, another way to ensure that both parents and children hold up their end of the bargain is for them to draw up and sign a legally enforceable contract (or at least an implicit or verbal contract).

To proceed with our technical analysis simply, we need to specify a quid pro quo bequest/care function. Note that care to parents can take many forms. We assume that care takes the form of a time sacrifice on the part of children (e.g., when they spend time interacting with, and entertaining, their parents or running errands for them). Certainly, it is not necessary to assume 
that parents and children are expected to always spend time together as nothing prevents an arrangement whereby, for example, a child paints her parent's fence while the latter is at work or on vacation elsewhere, but to simplify the analysis, we assume in our model that care always takes the form of spending time with parents. Fundamentally, even though spending time with parents entails various opportunity costs, the reward is a bequest.

Remark 8. Let us introduce the "care function" $z(\boldsymbol{v}, k(T), t)$, where $\boldsymbol{v}$ is the vector of functions, and assume that the care function is known and shaped by social customs and traditions. In line with the mathematical theory of optimal processes, let function $z$ be continuously differentiable in all of its arguments, none of which is a derivative. Assume that $0 \leq z(\boldsymbol{v}, k(T), t)<1$ and that $\frac{\partial z(\boldsymbol{v}, k(T), t)}{\partial k(T)}>0$. Hence, we assume that a ceteris paribus increase in the bequest amount $k(T)$ increases the amount of care time the child spends with her parent.

Note that time might enter function $z$ in the sense that, before some age, the expected care from one's child might be minimal since the parent is presumably healthy and busy at work but that it might increase rapidly with time as the parent ages and children mature. Vector $\boldsymbol{v}$ might include, among other things, the child's bargaining power and outside opportunities (that is, a child with better outside options would need to be promised a larger bequest to exert the same amount of care effort).

For any given bequest amount, the parent expects her child to spend $z(\boldsymbol{v}, k(T), t)$ fraction of time with the parent. For example, consider a parent who promises to bequeath $k(T)=$ $\$ 10,000$. Suppose that, at a certain point in time, the parent enjoys nine hours of non-sleep time as leisure, while social customs require that, in this case, the child spend one hour with the parent (i.e., $z(\boldsymbol{v}, k(T), t)=1 / 9$ ). Thus, the parent enjoys eight hours of leisure alone (away from the child) and one hour with the child. If the promised bequest amount increases to $\$ 20,000$, the child would promise to spend, say, an hour and a half with the parent $(z(v, k(T), t)=1 / 6)$ at time $t$. In this case, the parent enjoys seven and a half hours of leisure alone, and an hour and a half with the child.

Let the lifetime utility function of the main decision-maker now be

$$
\begin{aligned}
U=\int_{0}^{T} e^{-\rho t}( & \phi_{1} \ln [c(t)] \\
& +\phi_{2} \ln [(1-z(\boldsymbol{v}, k(T), t)) l(t)] \\
& \left.+\phi_{3} \ln [z(\boldsymbol{v}, k(T), t) l(t)]\right) d t
\end{aligned}
$$

Remark 9. We assume that the parent derives utility not only from leisure spent alone but also from leisure spent with her child. Note from $\left(1^{\prime}\right)$ that when the parent leaves a larger bequest to her child $(k(T)$ is greater), she ends up buying more joint time with the child, and thus, by definition, spends less time alone. There is a trade-off between leisure enjoyed privately and leisure enjoyed jointly with the child. Note, moreover, that the parent does not derive any utility directly from the amount of her bequest or the consumption of her child because she is not altruistic. The parent's bequest increases her utility only by increasing the amount of time she can spend with her child.

Let us for clarity of exposition denote terminal capital stock $k(T)$ as $B^{G}$. We now consider two separate assumptions about the care function, the first one being 
Assumption 1. Care is given by $z\left(\boldsymbol{v}, B^{G}, t\right)=z_{0} B^{G}$, where $z_{0}$ is positive yet small.

Under Assumption 1, we consider a truly simplistic case, where the care level is simply proportional to the amount of the assets bequeathed to the child. This greatly facilitates the analysis, yet leads (as will be seen shortly) to one-sided results. Following the same steps as in subsection 2.2, we can re-state the analogue of (12) as the first-order necessary condition for leisure:

$$
\frac{\partial H}{\partial l(t)}=\left(\phi_{2}+\phi_{3}\right) e^{-\rho t} l(t)^{-1}-\mu(t) w \epsilon(t)+\lambda(t)=0
$$

Hence, the analogues of (22) and (28) are

$$
a \equiv a\left(T_{\text {ret }}\right)=\left(\phi_{2}+\phi_{3}\right) /\left(w \epsilon\left(T_{r e t}\right)\right)
$$

and

$$
l(t)=\frac{\phi_{2}+\phi_{3}}{a\left(T_{r e t}\right) w \epsilon(t)}
$$

for $t \in\left[0, T_{\text {ret }}\right)$, respectively. We can thus rewrite (31) as

$$
\begin{aligned}
k\left(T_{\text {ret }}\right) \equiv \Lambda_{2}\left(T_{\text {ret }}\right) & \\
& =e^{r T_{r e t}} \int_{0}^{T_{r e t}}\left(w \epsilon(t)\left(1-\frac{\phi_{2}+\phi_{3}}{a\left(T_{r e t}\right) w \epsilon(t)}\right)\right. \\
& \left.-\frac{\phi_{1}}{a\left(T_{r e t}\right)}\right) e^{-r t} d t .
\end{aligned}
$$

Taking the limit of (31") as $r \rightarrow 0$, and equating the resulting expression with the analogue of (33) (where $\phi_{2}$ is replaced with $\phi_{2}+\phi_{3}$ ), we solve for the retirement age as follows:

$$
T_{r e t}\left(B^{G}\right)=\frac{-T \phi_{1}+\sqrt{D_{3}} / w}{\phi_{2}+\phi_{3}}
$$

where

$$
D_{3} \equiv w T\left(2 B^{G}\left(\phi_{2}+\phi_{3}\right)^{2}+w T \phi_{1}\left(\phi_{1}+2\left(\phi_{2}+\phi_{3}\right)\right)\right) \text {. }
$$

Thus, under Assumption 1, the optimal bequest amount can be computed as in Case 1, this time rewriting $\left(1^{\prime}\right)$ as (and recalling that $r=\rho=0$ )

$$
\Delta_{1}+\Delta_{2}
$$

where 


$$
\begin{aligned}
& \Delta_{1} \\
& \equiv \phi_{1} \int_{0}^{T_{r e t}\left(B^{G}\right)} \ln \left[\frac{\phi_{1}}{a\left(T_{\text {ret }}\left(B^{G}\right)\right)}\right] d t \\
& +\phi_{2} \int_{0}^{T_{\text {ret }}\left(B^{G}\right)} \ln \left[\frac{\phi_{2}+\phi_{3}}{a\left(T_{\text {ret }}\left(B^{G}\right)\right) w \epsilon(t)}\left(1-z\left(\boldsymbol{v}, B^{G}, t\right)\right)\right] d t \\
& +\phi_{3} \int_{0}^{T_{\text {ret }}\left(B^{G}\right)} \ln \left[\frac{\phi_{2}+\phi_{3}}{a\left(T_{\text {ret }}\left(B^{G}\right)\right) w \epsilon(t)} z\left(\boldsymbol{v}, B^{G}, t\right)\right] d t, \\
& \Delta_{2} \equiv \phi_{1} \int_{T_{\text {ret }}\left(B^{G}\right)}^{T} \ln \left[\frac{\phi_{1}}{a\left(T_{\text {ret }}\left(B^{G}\right)\right)}\right] d t \\
& +\phi_{2} \int_{T_{r e t}\left(B^{G}\right)}^{T} \ln \left[\left(1-z\left(\boldsymbol{v}, B^{G}, t\right)\right)\right] d t \\
& +\phi_{3} \int_{T_{r e t}\left(B^{G}\right)}^{T} \ln \left[z\left(\boldsymbol{v}, B^{G}, t\right)\right] d t .
\end{aligned}
$$

The optimal bequest amount is the amount that solves

$$
G \equiv \frac{\partial \Delta_{1}}{\partial B^{G}}+\frac{\partial \Delta_{2}}{\partial B^{G}}=0
$$

Unfortunately, even under Assumption 1, it is practically impossible to obtain $B_{o p t}^{G}$ from (41') as an explicit function of the exogenous parameters. However, let (41') implicitly define the optimal bequest amount as a function of exogenous parameters. Consequently,

$$
\frac{\partial B_{o p t}^{G}}{\partial \phi_{3}}=-\frac{\partial G / \partial \phi_{3}}{\partial G / \partial B_{o p t}^{G}}
$$

We verify that the right-hand side of (51) can be strictly positive around a range of points satisfying (41'), implying that an increase in $\phi_{3}$ might increase the optimal bequest amount. Using this fact and expression (35') (where we replace $B^{G}$ with $B_{o p t}^{G}$ ), we can compute the comparative statics as follows:

$$
\begin{aligned}
& \frac{\partial T_{r e t}^{o p t}}{\partial \phi_{3}} \\
& =\frac{-T \phi_{1}\left(w T\left(\phi_{1}+\phi_{2}+\phi_{3}\right)-\sqrt{D_{4}}\right)+\frac{\partial B_{o p t}^{G}}{\partial \phi_{3}} T\left(\phi_{2}+\phi_{3}\right)^{3}}{\left(\phi_{2}+\phi_{3}\right)^{2} \sqrt{D_{4}}},
\end{aligned}
$$

where

$$
D_{4} \equiv w T\left(2 B_{o p t}^{G}\left(\phi_{2}+\phi_{3}\right)^{2}+w T \phi_{1}\left(\phi_{1}+2\left(\phi_{2}+\phi_{3}\right)\right)\right) \text {. }
$$

Even when (51) is positive, the sign of $\left(50^{\prime}\right)$ is ambiguous. The same ambiguity is certainly observed when considering the number of hours worked during the working phase of life, which can be expressed as 


$$
L S(t)^{o p t} \equiv 1-l(t)^{o p t}=1+\frac{T_{r e t}^{o p t}-T}{T-t}
$$

Remark 10. Under Assumption 1, both the retirement age and hours worked move in the same direction in response to the rise in the strength of the exchange motive (see $\left(46^{\prime}\right)$ and $\left(50^{\prime}\right)$ ).

Intuitively, in the case of the quid pro quo strategic or exchange bequest motive, the decisionmaking parent wants to extract as much care as possible from her child and for that reason she wants to leave as large a bequest as possible, which follows from equation (51). This encourages the parent to maximize lifetime income, which in turn requires the parent to supply more labor and to retire later. However, in order to be able to afford to leave a larger bequest, the parent might want to reduce private consumption, which can be compensated for by increasing the amount of leisure. Interestingly, equation (46') implies that if the strategic or exchange bequest motive induces the parent to increase her labor supply at the intensive margin, it will also induce her to retire later, and conversely. Thus, both the retirement age and number of hours worked move strictly in the same direction under Assumption 1.

However, in reality, younger parents tend to have less need for care and attention from their children. Earlier in life, people are healthier and/or they find it harder to distract their children, who are at the early stages of their studies and career. More importantly, when parents are preoccupied with their work duties, they feel less lonely and less vulnerable. However, when they age and approach retirement age (and especially when they are less preoccupied with their formal work duties), their need for attention might increase. We thus propose an alternative specification for the care function, as given by the following assumption.

Assumption 2. Care is given by

$$
z\left(\boldsymbol{v}, B^{G}, t\right)=\frac{z_{1} B^{G}}{1+e^{z_{2}(1-l(t))}}
$$

where $z_{1}$ and $z_{2}$ are exogenous parameters.

Thus, under the second assumption, the care function takes a logistic form (which is differentiable) and again rises with the amount of bequest left, $B^{G}$. However, notice that during younger working ages (when $l(t)$ is small), the level of care is low. As the agent ages and thus approaches retirement $(l(t) \rightarrow 1)$, the care level demanded from the child can rise rapidly.

When care is given by (53), we can try to derive the analogue of $\left(12^{\prime}\right)$, which now will become much more complicated.

$$
\frac{\partial H}{\partial l(t)}=\left(\phi_{2} M_{1}+\phi_{3} M_{2}\right) e^{-\rho t} l(t)^{-1}-\mu(t) w \epsilon(t)+\lambda(t)=0,
$$

where

$$
M_{1} \equiv \frac{1-\frac{z_{1} B^{G}}{1+e^{z_{2}(1-l(t))}} M_{2}}{1-\frac{z_{1} B^{G}}{1+e^{z_{2}(1-l(t))}}},
$$




$$
M_{2} \equiv 1+\frac{e^{z_{2}(1-l(t))} l(t) z_{2}}{1+e^{z_{2}(1-l(t))}}
$$

We can see that, in Assumption 1, essentially $M_{1}=M_{2} \equiv 1$. Next, we obtain

$$
\begin{aligned}
& a \equiv a\left(T_{\text {ret }}\right) \\
& =\frac{\left(z_{1} B^{G}\left(2+z_{2}\right)-4\right) \phi_{2}+\phi_{3}\left(2+z_{2}\right)\left(z_{1} B^{G}-2\right)}{2 w \epsilon\left(T_{\text {ret }}\right)\left(z_{1} B^{G}-2\right)} .
\end{aligned}
$$

In what follows, it is important to solve (12") for leisure $l(t)$ when $\lambda(t)=0$ so that dynamic budget constraints can be used to pin down the optimal retirement age for a given terminal bequest level. Unfortunately, no closed-form solution exists in this case, which makes it extremely difficult to analytically infer the effect of a quid pro quo strategic or exchange bequest motive on the optimal retirement age and intensive labor supply. However, we have conducted a number of computations using various techniques as well as programmed simulations in GPOPS II (Patterson and Rao, 2014). Some interesting numerical results are provided in Table 1.

We observe from the last column of Table 1 that parents with a stronger quid pro quo strategic or exchange bequest motive bequeath more. The second and third columns show that the optimal retirement age and hours worked move in opposite directions. Hence, we conclude with the following

Remark 11. Under Assumption 2, it is possible that the stronger the quid pro quo strategic or exchange bequest motive, the larger the number of working hours and the earlier the retirement age, as shown by Table 1 .

\subsection{Summary}

To summarize, our theoretical model has shown that different types of bequest motives have different impacts on the work behavior of households. Households with a stronger altruistic bequest motive unambiguously work more hours and retire later than households with a weaker bequest motive, but the impact of a strategic or exchange bequest motive on work behavior is theoretically ambiguous. Households with a stronger strategic or exchange bequest motive may work more or fewer hours and retire earlier or later than households with a weaker strategic or exchange bequest motive.

It is entirely possible that some parents would expect much more care specifically during the retirement stage, while in general some parents would seek greater attention when they are less preoccupied with their current jobs. The flexibility of (53) allows us to generate various shapes for the care function. Under different parameterisations, the impact of a strategic or exchange bequest motive on the timing of retirement can still be ambiguous because, on the one hand, the parent wants to work longer to increase her lifetime income and the amount of her bequest in order to elicit more care from children, while on the other hand, she might want to retire earlier so she can start receiving care from her children sooner. Thus, when a strong strategic or exchange bequest motive is present, bequest motives have a complex impact on various 
margins of work behavior. A careful empirical analysis is needed to shed light on these interactions, and this is precisely what we do in section 3.

\section{Empirical Analysis}

In this section, we present the results of our empirical analysis of the impact of bequest motives on the retirement behavior of households in Japan using micro data from the Preference Parameters Study of Osaka University. More specifically, in subsection 3.1, we derive testable hypotheses for a Japanese individual from our theoretical analysis; in subsection 3.2, we explain our data source and sample selection criteria; in subsection 3.3, we explain our estimation model and variable definitions; in subsection 3.4, we conduct a univariate analysis of individual work behavior under different bequest motives; and in subsection 3.5, we present and interpret our estimation results.

\subsection{Hypothesis Development}

In this subsection, we derive testable hypotheses from our theoretical analysis in section 2 . Our theoretical model predicts that a parent with a stronger altruistic bequest motive will leave a larger bequest to her children and thus work more at both the intensive margin (see Remark 7 on page 11). Thus, the testable hypothesis regarding the altruistic bequest motive is as follows:

H1: The stronger an individual's altruistic bequest motive, the larger the bequest she will leave to her children and the more she will work at both the intensive and extensive margins.

By contrast, our theoretical model reveals that an individual with a strategic or exchange bequest motive confronts a dilemma. On the one hand, she wants to work more in order to be able to earn more, to leave a larger bequest to her children, and to elicit more care from them, but on the other hand, she wants to work less so that she can spend more time with (and receive more care from) her children. As a result, the net impact of this type of bequest motive on the amount of work at the intensive margin ( see Remark 11 on page 16) is ambiguous. However, since the social norm in Japan is to work hard, a Japanese individual may work more at the intensive margin (for example, work more hours per week) in order to earn more, to leave a larger bequest to her children, and to elicit more care from them, but retire earlier in order to be able to start receiving care from her children sooner. Thus, the testable hypothesis regarding the strategic or exchange bequest motive is as follows:

H2: An individual with a strategic or exchange bequest motive will work more at the intensive margin but work less at the extensive margin (i.e., retire earlier).

Hypothesis $\mathrm{H} 1$ is framed in terms of a continuous variable measuring the strength of the altruistic bequest motive, and $\mathrm{H} 2$ is framed in terms of a variable measuring how much value the parent places on spending time with her children, but as discussed in subsection 3.2 below, we only have discrete information on whether or not respondents have each type of bequest motive. Therefore, we test these hypotheses by analyzing how the work behavior of a respondent with an altruistic or strategic/exchange bequest motive compares with that of a respondent with no bequest motive whatsoever. 


\subsection{Data Source and Sample Selection Criteria}

In this subsection, we discuss the data source we use for our analysis and our sample selection criteria. We use micro data from the 2012 wave the Preference Parameters Study (Kurashi no Konomi to Manzokudo ni tsuite no Chousa) of Osaka University, a panel survey that was conducted in Japan and three other countries by the 21st Century Center of Excellence (COE) Program "Behavioral Macrodynamics Based on Surveys and Experiments" and the Global COE Project "Human Behavior and Socioeconomic Dynamics" of Osaka University. The survey was conducted annually during the 2003-13 period, but we chose to use data from the 2012 wave because the question about bequest motives was not asked in every year and 2012 was the most recent year for which this question was asked. The survey collects data on a nationwide random sample of both sexes, and the 2012 survey had 4588 respondents.

The micro data from the 2012 wave is perfectly suited for our purposes because it collects detailed information on bequest motives, working hours, employment status (full-time vs. parttime), planned retirement age, and all of the other variables that we need for our analysis. The complete survey instrument (questionnaire form) for the survey that we used for this analysis can be found at the following website:

https://www.iser.osaka.ac.jp/survey_data/doc/japan/questionnaire/english/2012QuestionnaireJAPAN.pdf

Since the data source we used is a panel survey, it would have been preferable to do a panel analysis with fixed effects to control for individual heterogeneity, but unfortunately, we were not able to do so because some questions such as the ones pertaining to bequest motives were not asked in every wave. Fortunately, however, the survey we used collects information on a multitude of individual and household attributes, so we were able to control for such heterogeneity by including a large number of individual- and household-related covariates.

The sample selection criteria we used are as follows:

(1) We dropped all observations for which there were missing values for at least one of the variables used in the estimations.

(2) We dropped all observations for which respondents are not currently working.

(3) We dropped all observations for which respondents have no children because we were interested in examining whether respondents' intention of leaving bequests to their children has any impact on their work behavior.

(4) Since the value of the wage rate (WAGE) was unreasonably high or low in some cases due to the reported number of hours worked being unreasonably high or low, we dropped all observations that were in the top $1 \%$ or the bottom $1 \%$ of the distribution of WAGE.

\subsection{Estimation Model and Variable Definitions}

In this subsection, we describe the estimation model and the variables we use from the survey questions to test the hypotheses regarding the impact of bequest motives on individuals' work behavior that we derived and discussed in the subsection 3.1. The question number in parentheses for each variable shows the survey question we used to construct that variable. 
The estimation model for an individual i's work behavior is as follows:

$y_{i}=\alpha_{0}+\alpha_{a} b m_{a i}+\alpha_{c} b m_{c i}+\alpha_{f} b m_{f i}+\alpha_{b} b m_{b i}+\alpha_{w} b m_{w i}+\beta^{\prime} x_{i}+\varepsilon_{i}$

where $y_{i}$ is the dependent variable that represents work-related outcomes for the intensive and extensive margins for individual $i$ as defined below:

Log(HRSPERWEEK) = the natural logarithm of the number of hours the respondent is working per week (a measure of the intensive margin, survey question B9), and

$\log ($ RETAGE $)=$ the natural logarithm of the age at which the respondent plans to retire (a measure of the extensive margin, survey question B12).

HRSPERWEEK pertains to the intensive margin (i.e., how much the respondent works during a given period of time, given that he or she works) whereas RETAGE pertains to the extensive margin (i.e., how long the respondent plans to work before retiring completely). We estimate a separate equation for each of these two dependent variables ${ }^{4}$. More precisely, we estimate the HRSPERWEEK and RETAGE equations using ordinary least squares.

In addition, we use the probability of working full-time as an alternate measure of the intensive margin in our robustness checks to be presented later.

FULLTIME $=1$ if the respondent is working full-time and 0 if the respondent is working parttime (survey question B13b),

The explanatory variables pertaining to bequest motives in the estimation model above $(\mathrm{bm})$, which are of most interest for our purposes, are as follows:

BEQMOTALT $\left(\mathrm{bm}_{a}\right)=1$ if the respondent is planning to leave a bequest to his or her child(ren) under any circumstances and 0 otherwise (survey question A31)

BEQMOTCARE $\left(b m_{c}\right)=1$ if the respondent is planning to leave a bequest to his or her child(ren) only if his or her child(ren) provide care (including nursing care) during old age and 0 otherwise (survey question A31)

BEQMOTFIN $\left(b m_{f}\right)=1$ if the respondent is planning to leave a bequest to his or her child(ren) only if his or her child(ren) provide financial assistance during old age and 0 otherwise (survey question A31)

\footnotetext{
${ }^{4}$ It is quite possible that the two work-related variables-number of hours worked per week and planned retirement age-are seemingly contemporaneously correlated. For example, an individual who plans to retire earlier may choose to work for more hours per week. This can make the error terms of the two work-related dependent variables (Log(RETAGE) and Log(HRSPERWEEK)) contemporaneously correlated. These equations can be estimated jointly using the Seemingly Unrelated Regression (SUR) method. However, the joint (SUR) estimates and the single equation (ordinary least squares or OLS) estimates are identical when the right-hand side variables are the same. In our case, the right-hand side variables are the same in the two equations, and hence we estimate each equation separately.
} 
BEQMOTBUS $\left(b m_{b}\right)=1$ if the respondent is planning to leave a bequest to his or her child(ren) only if his or her children carry on the family business and 0 otherwise (survey question A31)

BEQMOTWEAK $\left(b m_{w}\right)=1$ if the respondent does not plan to make special efforts to leave a bequest to his or her child(ren) but will leave whatever is leftover and 0 otherwise (survey question A31)

We regard BEQMOTALT as an altruistic bequest motive because the respondent does not impose any preconditions for leaving a bequest, and we regard BEQMOTCARE, BEQMOTFIN, and BEQMOTBUS as strategic or exchange bequest motives because the respondent imposes preconditions for leaving a bequest in all three cases. The default categories are respondents who do not plan to leave a bequest to their children under any circumstances and respondents who want to leave a bequest to their children but will not because they do not have the financial capacity to do so. Since we benchmark on individuals with no bequest motive ${ }^{5}$, the $\alpha^{\prime} s$ measure the impact of each type of bequest motive on the individual's work behavior. For instance, the sign and significance of $\alpha_{a}$ and $\alpha_{c}$ can shed light on the impact of altruistic and strategic or exchange bequest motives on work behavior as stated in $\mathrm{H} 1$ and $\mathrm{H} 2$ above, respectively.

To control for the impact of other individual- and household-specific factors on the three workrelated outcomes, we include the following variables in vector $x$ following, for example, Brown et. al (2015), Farhi et. at (2007), and Honig (1998), among others:

$\log ($ WAGE) $=$ the natural logarithm of the respondent's wage rate (hourly wage) (survey questions B9 and B18)

In the data source we used, respondents have a choice between writing down his or her monthly salary or his or her hourly wage. For respondents who wrote down their hourly wage, we used this information as is, but for respondents who wrote down their monthly salary, we converted their monthly salary to an hourly wage by dividing their monthly salary by the number of hours worked per month. Since respondents are asked to report the number of hours they work per week, we converted it to the number of hours they work per month by multiplying it by 52, then dividing by 12 (or by multiplying by 4.33333 ).

Since the work decisions of respondents will be affected by the earned income of other household members, we also include the respondent's household earned income excluding the respondent's own earned income:

$\log ($ OTHERINC) $=$ the natural logarithm of non-respondent earned income, which was calculated as the respondent's household earned income excluding the respondent's own earned income (survey questions B19 and B36)

\footnotetext{
5 "No bequest motive" includes the following three out of eight responses to the bequest motive question in the survey: "the repondent does not plan to leave a bequest to his or her child(ren) under any circumstances because doing so may reduce their will to work," "the respondent does not plan to leave a bequest to his or her child(ren) under any circumstances because he or she wants to use his or her wealth himself or herself," and "the respondent wants to leave a bequest to his or her chid(ren) but he or she won't because he or she does not have the financial capacity to do so.”
} 
BEQREC $=1$ if the respondent has received a bequest (including real and financial assets) with a total value of 5,000,000 yen or more from his or her parents or parents-in-law in the past and 0 otherwise (survey question A32)

$\mathrm{BEQEXP}=1$ if the respondent expects to receive a bequest (including real and financial assets) with a total value of 5,000,000 yen or more from his or her parents or parents-in-law in the future and 0 otherwise (survey question A33)

We include wealth-related variables such as WAGE, OTHERINC, BEQREC, and BEQEXP to eliminate the possibility that bequest motives are merely acting as a proxy for wealth, and we believe that BEQREC and BEQEXP are especially suitable for this purpose because they are largely exogenous, being the decision of the respondent's parents.

Furthermore, we include the following personal and work-related attributes of the respondent to eliminate the possibility of omitted variable(s) (endogeniety) bias that can bias the bequestwork relationship due to the model's errors $\left(\varepsilon_{i}\right)$ being correlated with bequest motives ${ }^{6}$ :

MALE $=1$ if the respondent is male and 0 if the respondent is female (survey question B1)

MARRIED = 1 if the respondent is married or cohabiting with a partner and 0 if the respondent is never married, divorced, widowed, or separated and in the process of getting divorced (survey question B2)

$\log ($ AGE $)=$ the natural logarithm of the respondent's current age (survey question B4)

HEALTH = the respondent's health status on a scale of 1 to 5 (with 5 being the highest) (survey question B51)

WORRY = the extent to which the respondent is worried about his or her life after age 65 (future life in the case of respondents who are 65 or older) on a scale of 1 to 5 (with 5 being the highest) (survey question A1)

WORK = the extent to which the respondent feels that "work is something to live for" on a scale of 1 to 5 (with 5 being the highest) (survey question A1)

WORKSAT $=$ the extent to which the respondent is satisfied with work on a scale of 1 to 5 (with 5 being the highest) (survey question B18)

SALWKR $=1$ if the respondent is a salaried worker and 0 if the respondent is self-employed or a family worker (survey question B13a)

PENSION = the proportion of the living expenses after the retirement of the respondent and his or her spouse (if any) that the respondent expects to be able to cover using public pension benefits (in percent) (survey question B42)

NUMCHILDREN = the number of children the respondent has (survey question B15)

\footnotetext{
${ }^{6}$ For example, omitting MALE may cause $\varepsilon_{i}$ to be correlated with bequest motives $(\mathrm{bm})$ since males are the main contributor to household wealth in Japan.
} 
GAMBLE $=1$ if the respondent gambles at least several times a year and 0 otherwise (included as a proxy for the degree of risk aversion) (survey question B57)

We believe that our estimates are free from reverse relationship (endogeneity) bias-a bias arising from the fact that the respondent works hard simply because he/she enjoys working, that he/she ends up being able to accumulate more wealth than he/she can use himself/herself because he/she works harder, and that this makes it easier for him//her to leave a bequest-because a reverse relationship is more likely to be observed for older workers (who are more likely to have accumulated a significant amount of wealth) whereas our results are driven by younger workers (as we show later). Moreover, we include WORK and WORKSAT (both of which are presumably fundamental or exogenous variables) to eliminate the possibility of reverse relationship bias. Note, finally, that, even if including WORK and WORKSAT is not sufficient to eliminate reverse relationship bias, the survey we used lists five types of bequest motives (BEQMOTALT, BEQMOTCARE, BEQMOTFIN, BEQMOTBUS, and BEQMOTWEAK), and respondents who accumulate more wealth than they can use themselves because they enjoy working will presumably be more likely to have a weak (unintended) bequest motive (BEQMOTWEAK) rather than an altruistic bequest motive (BEQMOTALT) or a strategic or exchange bequest motive for care (BEQMOTCARE). For all of these reasons, reverse relationship bias is unlikely to be applicable in the case of our main variables of interest. ${ }^{7}$

\subsection{Univariate Analysis}

In this subsection, we conduct a univariate analysis of the variables relating to work behavior and bequest motives. As can be seen from Table 2, the mean values of the three work-related outcomes are as follows: $59.4 \%$ of the sample works full-time, the average number of hours worked per week is 41.3 , and the average planned retirement age is 64.7 years. The average planned retirement age is reasonable because, in Japan, the mandatory retirement age (and the age at which workers can start receiving public pension benefits) are in the process of being raised from 60 to 65 .

As for bequest motives, $29.4 \%$ of the sample has an altruistic bequest motive, $3.0 \%$ of the sample has a strategic or exchange bequest motive pertaining to providing care to parents, $0.8 \%$ of the sample has a strategic or exchange bequest motive pertaining to providing financial assistance to parents, $0.8 \%$ of the sample has a strategic or exchange bequest motive pertaining to carrying on the family business, $47.3 \%$ of the sample has a weak bequest motive, and $18.7 \%$ of the sample has no bequest motive at all.

Among the strategic or exchange bequest motives, we confine our discussion to the motive pertaining to providing care to parents because this is the motive that is closest in spirit to our theoretical model and because the shares of the other strategic or exchange bequest motives are

\footnotetext{
${ }^{7}$ Moreover, respondents who worked for many hours per week and accumulated considerable wealth as a result may or may not choose to leave a bequest. For example, Andrew Carnegie strongly opposed leaving inheritances to one's children even though he worked hard and became one of the world's wealthiest men because he felt that it would weaken their will to work and to contribute to society (see Carnegie, 1962; this motive corresponds to the first response in footnote 5). Indeed, he set an example by giving away all of his massive wealth to charitable causes and leaving nothing to his daughter, and there are many other wealthy individuals who behave similarly. Thus, we believe that bequest decisions arise from deep parameters that are exogenous and that whether or not one has a bequest motive is independent of one's work effort or wealth level.
} 
less than $1 \%$ of the sample. Moreover, the weak bequest motive is not related to $\mathrm{H} 1$ and $\mathrm{H} 2$ so we do not discuss the results for this motive either although we include all bequest motives in the estimation model so we can estimate the partial effects $\alpha_{a}$ and $\alpha_{c}$ of the bequest motives in which we are interested, i.e., BEQMOTALT $\left(b m_{a}\right)$ and BEQMOTCARE $\left(b m_{c}\right)$.

Before turning to our regression analysis, we present the results of our univariate analysis of the bequest-work relationship (as hypothesized in $\mathrm{H} 1$ and $\mathrm{H} 2$ ) in Table 3 with the average values of the two work-related outcomes being broken down by bequest motive. We can see from this table that the outcome variables differ substantially by bequest motive in systematic ways. For example, respondents with an altruistic bequest motive (those who plan to leave a bequest to their children under any circumstances) show higher values of both outcome variables than other respondents: i.e., they work more hours per week and plan to retire later. By contrast, respondents with a strategic or exchange bequest motive for care (those who plan to leave a bequest to their children only if they provide care (including nursing care) during old age) work more hours per week but plan to retire earlier than other respondents.

Our theoretical model showed that those with an altruistic bequest motive work more and retire later than others but that those with a strategic or exchange bequest motive tend to work more but retire earlier than others. Thus, our preliminary findings based on univariate analysis are fully consistent with $\mathrm{H} 1$ and $\mathrm{H} 2$ regarding the bequest-work relationship. However, we need to see whether these findings hold even after we control for the impact of individual- and household-specific factors on the two work-related outcomes using regression analysis, which is what we do in the next subsection.

\subsection{Estimation Results and Empirical Findings}

In this subsection, we present and discuss the estimation results of our econometric model in equation (56) for the work behavior of individuals in Japan with emphasis on the impact of the bequest motives of interest $\left(\alpha_{a}, \alpha_{c}\right)$ thereon. More specifically, we present and discuss the estimation results for the two (dependent) variables - one for work at the intensive margin, i.e., the number of hours worked per week and the other for work at the extensive margin, i.e., the planned retirement age. Our interest in individual- and household-specific factors $(x)$ is limited to controlling for their impact on individuals' work behavior.

\subsubsection{The bequest-work relationship}

We present the estimation results for the bequest-work relationship in Tables 4-5. Table 4 shows the results for the number of hours worked per week, while Table 5 shows the results for the planned retirement age, both estimated using ordinary least squares.

We show estimation results for the full sample, for the married sample, for the male sample, and for the married male sample for all ages and for those aged 40 or older because work behavior tends to differ by marital status, gender, and age and because this may help us to find the subsample, if any, that drives the bequest-work relationship in the full-sample. As discussed earlier, we are interested primarily in the altruistic bequest motive and the strategic or exchange bequest motive for care, and we present these results under "bequest motives of interest" in Tables 4-5. 
We find that $\alpha_{a}$ is positive and statistically significant at the $10 \%$ levels for the full sample (see the column marked "Both sexes, all ages") in log(HRSPERWEEK) regression, as shown in Table 4. Thus, as in the case of our univariate analysis, the number of working hours per week of respondents with an altruistic bequest motive (BEQMOTALT) is significantly higher than that of respondents without any bequest motive. However, we do not find similar support for respondents' planned retirement age as $\alpha_{a}$ is statistically insignificant in the $\log ($ RETAGE) regression, as shown in Table 5. The fact that more significant results are obtained for all ages than for the 40-plus sample in the log(HRSPERWEEK) regression suggests that the significant altruistic bequest-work relationship for the full sample appears to be driven by respondents who are less than 40 years old, which in turn suggests that altruistic respondents modify their work behavior at a relatively early age. Thus, we find partial support for H1 (i.e., an altruistic bequest-work relationship) in the case of Japan.

Our empirical results pertaining to $\mathrm{H} 2$ are consistent with theoretical predictions as well as with the univariate analysis discussed in subsection 3.4 for both work-related outcomes. We find that $\alpha_{c}$, which measures the strength of the strategic or exchange bequest-work relationship, is positive and statistically significant at the $5 \%$ level for the full sample (see the column marked "Both sexes, all ages"), as shown in Table 4, and negative and statistically significant at the $5 \%$ level in the log(RETAGE) regression, as shown in Table 5 . These results imply that the number of hours worked per week of respondents who plan to leave a bequest only if their children provide care (including nursing care) during old age (BEQMOTCARE) is significantly higher but that their planned retirement age is significantly lower than that of respondents without any bequest motive. These results provide strong support for $\mathrm{H} 2$.

Looking at the results for various subsamples, the strategic or exchange bequest-work relationship is stronger for the male sample than for both sexes in the log(HRSPERWEEK) regressions (in fact, $\alpha_{c}$ is statistically significant at the $1 \%$ level in the male sample of all ages). This suggests that the strategic or exchange bequest motive affects the number of hours worked per week of male respondents more than that of female respondents and that male respondents are the ones driving the results for the full sample.

Moreover, the strategic or exchange bequest-work relationship is stronger for the married male sample than for the full male sample in the log(RETAGE) regression. This suggests that the strategic or exchange bequest motive affects the planned retirement age of married males more than it affects that of unmarried males, which suggests that it is married males who are driving the results for the full sample (our unreported results for female respondents provide further support for this claim). A possible explanation for this finding is that married males have a greater demand for care from their children because they as well as their wives are potential care recipients ${ }^{8}$.

Our interpretation of the strategic or exchange bequest-work relationship is that respondents with a strategic or exchange bequest motive tend to work more intensively than others before they retire so that they can earn more, leave a larger bequest to their children, and elicit more care from them after they retire but that they tend to retire earlier than others so that they can start receiving care from their children sooner.

${ }^{8}$ Our unreported results indicate that the strategic or exchange bequest-work relationship is supported for respondents aged less than 50 years old. In other words, the bequest-work relationship is driven by relatively young married couples in general and young married males in particular. This makes sense since planning for bequests and retirement is an issue for young working couples with children. 
Comparing our results for the altruistic and strategic/exchange bequest motives, $\alpha_{c}$ is more than twice as large as $\alpha_{a}$ in almost all cases, as can be seen from Tables 4 and 5, implying that the strategic or exchange bequest motive (whereby parents leave a bequest to their children in exchange for receiving care) has a much greater impact on their employment status and working hours than the altruistic bequest motive (whereby parents give a unilateral transfer to their children without receiving anything in return).

\subsubsection{The impact of other factors on work behavior}

In this subsection, we discuss our findings relating to the other factors that can affect the various work-related outcomes considered in the estimation model. We included the sixteen control variables discussed in subsection 3.2, plus the natural logarithm of wage squared to account for possible non-linearity in the impact of wages. We provide explanations of the factors that are relevant and important in the Japanese context.

\subsubsection{Wages and other income}

The net effect of the respondent's wage rate (WAGE) on the number of hours worked per week is positive. More specifically, the marginal effect of an increase in the wage rate is $\frac{\frac{\partial y}{y}}{\frac{\partial w}{w}}=\beta_{1}+$ $2 \beta_{2}$, where $w$ is the wage rate, which equals $1.097+2 \times(-0.081)=0.935$ for the full sample in the $\log$ (HRSPERWEEK) regression (see the column marked "Both sexes, all ages" in Table 5). The effect seems to be intuitively reasonable as it implies that a one percentage point increase in the wage rate increases the number of hours worked per week by less than one percentage point.

By contrast, the respondent's wage rate has a consistently negative and statistically significant impact on the planned retirement age, as shown in Table 6, presumably because leisure is a luxury good, the demand for which increases (causing a decline in labor supply) as income increases. More specifically, the marginal effect of an increase in the wage rate is $-0.161+$ $2 \times(0.01)=-0.141$ for the full sample in the $\log (\mathrm{RETAGE})$ regression (see the column marked "Both sexes, all ages" in Table 6).

As expected, an addition to non-respondent earned income (OTHERINC) induces respondents to retire earlier, again presumably reflecting the fact that leisure is a luxury good.

\subsubsection{Bequest receipts and bequest expectations}

Bequest receipts (BEQREC) and bequest expectations (BEQEXP), both of which are a measure of nonwage income, should have qualitatively similar impacts as non-respondent earned income (OTHERINC) on individual work behavior, but the impact of BEQREC is never statistically significant, while BEQEXP has a negative and statistically significant impact in the $\log (\mathrm{RETAGE})$ regression. The latter finding implies that respondents expecting to receive bequests plan to retire earlier than respondents without such expectations, as expected.

\subsubsection{Gender, age, and marital status}


The impact of gender (MALE) is significantly positive as expected, reflecting the social norm in Japan that males are expected to work more than females both at the intensive and extensive margins.

As for the impact of marital status (MARRIED), being married shortens working time significantly at both the intensive and extensive margins in the full sample but does not have a significant impact on working time in the male sample. Our finding for the male sample may arise because the desire of married males to spend time with their wives and children, which would tend to reduce their working time, is offset by the social norm in Japan that wives bear a disproportionate share of the burden of housework and childrearing, which would enable married males to increase their working time.

The respondent's age (AGE) has a negative and statistically significant impact on the number of hours worked per week but has a positive and statistically significant impact on the planned retirement age. The former finding is plausible because mental and/or physical fatigue presumably increases with age, reducing how much the respondent can work at the intensive margin. The latter finding suggests that respondents postpone retirement as they get older, perhaps because they gradually realize that they do not have enough resources to finance their living expenses during retirement.

\subsubsection{Work importance, work satisfaction, and occupation type}

The importance of work (WORK) generally has a positive and statistically significant impact on the number of hours worked per week and on the planned retirement age, meaning that respondents for whom work is more important work more and work longer, which is as one might expect.

As expected, work satisfaction (WORKSAT) has a positive and statistically significant impact on the extensive margin (i.e., the planned retirement age), meaning that respondents who are satisfied with work, work longer but this is not the case at the intensive margin.

As for the impact of occupation type (SALWKR), salaried workers plan to retire earlier than the self-employed. This result is as one might expect because salaried workers face a mandatory retirement age, whereas the self-employed do not, and because the pension benefits of salaried workers are higher than those of the self-employed in Japan.

\subsubsection{Public pension benefits}

The generosity of public pension benefits (PENSION) has a negative and statistically significant impact on the number of hours worked per week and on the planned retirement age (Honig (1998) reports similar results for a sample of 590 white married women in the United States). This is evidence of the induced retirement effect identified by Feldstein (1974).

\subsubsection{Number of children}

As for the impact of the number of children (NUMCHILDREN), it does not have a significant impact on either work-related outcome.

\subsubsection{Risk preference, health status, and worry about retirement}


As for the impact of the degree of risk aversion (GAMBLE), risk-loving respondents who like to gamble do not differ significantly from other respondents for the number of hours worked per week or for their planned retirement age in the case of both sexes. Farhi and Panageas (2007) find that individuals who wish to retire earlier are less risk-averse and invest more in the stock market, but our finding that there is not a statistically significant association between the degree of risk aversion and the timing of retirement implies that Farhi and Panageas's (2007) finding does not apply in the case of Japan. However, this result might be due to the weak proxy we use for risk aversion.

The health status (HEALTH) of males delays their planned retirement age, which is in line with the findings of Brown et al. (2015), who report that Croatian retirees in good health are more likely to opt for a deferred retirement package.

Finally, worry about life after 65 (WORRY) does not have a statistically significant impact on either work-related outcome.

\subsection{Robustness Checks}

In this section, we discuss the large number of robustness checks that we conducted for our empirical analysis. First, we used the probability of working full-time as an alternative measure of the intensive margin. The model is estimated using the probit method. The results are shown in Table 6 for the marginal effects, and as can be seen from this table, the results are generally very similar to those for the number of hours worked per week, especially for the bequest motive-related variables that are of the most interest to us. Even though working full-time is a weak proxy for work at the intensive margin because it is not a continuous variable, it shows that individuals with an altruistic or strategic/exchange bequest motive work more than individuals with no bequest motive at all, as we found when we used the number of hours worked per week.

We also conducted a battery of other robustness checks, but our main empirical results of the bequest-work relationship remained unchanged and significant. For example, we restricted our sample to households with at least one child since bequest allocation is a parent-child issue. We also added a long list of individual- and household-specific controls to eliminate the endogeneity bias arising from omitted variable(s). Moreover, our results are free from reverse relationship bias, as discussed earlier. We also eliminated the possibility that bequest motives are merely acting as a proxy for wealth by including a large number of wealth-related variables such as WAGE, WAGE ${ }^{2}$, OTHERINC, BEQREC, and BEQEXP.

\section{Conclusion and Policy Implications}

In this paper, we conducted a theoretical and empirical analysis of the impact of bequest motives on the work and retirement behavior of households in Japan using micro data from the Preference Parameters Study of Osaka University to shed light on whether or not households planning to leave bequests work more or work longer than those not planning to leave bequests. Our empirical findings are consistent with our theoretical model and show that respondents with an altruistic or strategic/exchange bequest motive work more at the intensive margin than those without any bequest motive but that respondents with a strategic or exchange bequest motive work less at the extensive margin (i.e., retire earlier) than those without any bequest 
motive. Our findings for the strategic or exchange bequest motive are entirely plausible because respondents with such a motive may want to work harder than others before they retire so that they can earn more, leave a larger bequest to their children, and elicit more care from them but that they may want to retire earlier than others so that they can start receiving care for themselves and their spouses from their children sooner. Moreover, the altruistic bequest-work relationship in Japan is driven by relatively young respondents (those aged less than 40 years), which suggests that altruistic respondents decide their work behavior at a relatively young age. Interestingly, the strategic or exchange bequest-work relationship is driven primarily by the married male sample. A possible explanation for this finding is that married males have a greater demand for care from their children because they as well as their wives are potential care recipients.

We employ a battery of robustness checks to show that our empirical findings concerning the bequest-work relationship are highly robust, remaining significant and consistent with the predictions of our theoretical model even when (i) we use a dummy variable for full-time work in lieu of the number of hours worked per week as a measure of the intensive margin, (ii) we include a large number of control variables relating to individual- and household-specific factors to address the endogeneity bias arising from omitted variable(s), (iii) we ensure that the bequest-work relationship is free from reverse relationship bias, and (iv) we add a number of proxies for wealth to eliminate the possibility that bequest motives are merely acting as a proxy for wealth.

Our findings have important implications for policymakers in Japan. Since individual work behavior can be altered by changing inheritance taxes, it is very important for policymakers to realize that the bequest-work relationship exists but that it varies by bequest motive in Japan. In the case of a strategic or exchange bequest motive, which affects parents' work behavior as well as retirement decision, inheritance tax policy should be set taking account both the increased work effort at the intensive margin as well as the induced retirement effect of this motive. On one hand, a lower inheritance tax will encourage parents to work more before retirement so they can leave a larger bequest, and this will contribute to higher economic growth. However, a lower inheritance tax may also lead some parents to retire earlier than otherwise so that they can start receiving care sooner, meaning that labor supply may not increase, on balance, as a result of a reduction in the inheritance tax. In the case of the altruistic bequest motive, by contrast, there does not seem to be any need to worry about the induced retirement effect, meaning that lowering inheritance taxes will unambiguously increase work efforts by encouraging individuals to leave bequests. Since the rapid ageing of Japan's population is projected to produce severe shortages of workers in the coming years, reforming inheritance taxes and other government policies relating to bequests may be an effective way of encouraging people to work more, if implemented carefully. 


\section{References}

Arrondel, Luc, and Masson, Andre (2006), “Altruism, Exchange or Indirect Reciprocity: What Do the Data on Family Transfers Show?” in Serge-Christophe Kolm and Jean Mercier Ythier, eds., Handbook of the Economics of Giving, Altruism and Reciprocity, Volume 2 (Amsterdam: Elsevier B.V.), pp. 971-1053.

Bagchi, Shantanu (2015), "Labor supply and the optimality of Social Security,” Journal of Economic Dynamics and Control, vol. 58 (Sept.), pp. 167-185.

Bernheim, B. Douglas; Shleifer, Andrei; and Summers, Lawrence H. (1985), “The strategic bequest motive,” Journal of Political Economy, vol. 93, no. 6 (Dec.), pp. 1045-1076.

Blau, David M., and Goodstein, Ryan M. (2016), "Commitment in the household: Evidence from the effect of inheritances on the labor supply of older married couples," Labour Economics, vol. 42 (Oct.), pp. 123-137.

Blau, Francine D., and Kahn, Lawrence M. (2007), "Changes in the labor supply behavior of married women: 1980-2000,” Journal of Labor Economics, vol. 25, no. 3 (July), pp. 393438.

Brown, Jeffrey R.: Coile, Courtney C.; and Weisbenner, Scott J. (2010), “The effect of inheritance receipt on retirement," Review of Economics and Statistics, vol. 92, no. 2 (May), pp. 425-434.

Brown, Jeffrey R.; Ivkovic, Zoran; and Weisbenner, Scott (2015), "Empirical determinants of intertemporal choice,” Journal of Financial Economics, vol. 116, pp. 473-486.

Bütler, Monika (2001), “Neoclassical life-cycle consumption: A textbook example,” Economic Theory, vol. 17, no. 1 (Jan.), pp. 209-221.

Carnegie, Andrew (1962), "The Advantages of Poverty," in Edward C. Kirkland, ed., The Gospel of Wealth and Other Timely Essays (Cambridge, Massachusetts, USA: The Belknap Press of Harvard University), pp. 50-77.

Dimova, Ralitza, and Wolff, François-Charles (2011), "Do downward private transfers enhance maternal labor supply? Evidence from around Europe," Journal of Population Economics, vol. 24, no. 3 (July), pp. 911-933.

Doorley, Karina, and Pestel, Nico (2016), "Labour supply after inheritances and the role of expectations,” IZA Discussion Paper No. 9822, Institute of Labor Economics (IZA), Bonn, Germany.

Dustmann, Christian; Micklewright, John; and Soest, Arthur (2009), "In-School Labour Supply, Parental Transfers, and Wages,” Empirical Economics, vol. 37, no. 1 (Sept.), pp. 201-218.

Elinder, Mikael; Erixson, Oscar; and Ohlsson, Henry (2012), “The impact of inheritances on heirs labor and capital income,” BE Journal of Economic Analysis and Policy, vol. 12, no. 1, pp. 1-37. 
Farhi, Emmanuel, and Panageas, Stavros (2007), "Saving and investing for early retirement: A theoretical analysis,” Journal of Financial Economics, vol. 83, no. 1 (Jan.), pp. 87-121.

Feldstein, Martin (1974), "Social security, induced retirement, and aggregate capital accumulation,” Journal of Political Economy, vol. 82, no. 5 (Sept.-Oct.), pp. 905-926.

Gahramanov, Emin, and Tang, Xueli (2016a), "Impatient in experiments, but patient in simulations: A challenge to the Heckman-type model,” Economic Record, vol. 92, no. 297 (June), pp. 268-290.

Gahramanov, Emin, and Tang, Xueli (2016b), "Labor-leisure choice: Is everything as straightforward as one might have thought?,” Theoretical Economics Letters, vol. 6, no. 4 (Aug.), pp. 750-760.

Gong, Tao (2009), “Do parental transfers reduce youths' incentives to work?” LABOUR: Review of Labour Economics and Industrial Relations, vol. 23, no. 4 (Dec.), pp. 653-676.

Holtz-Eakin, Douglas; Joulfaian, David; and Rosen, Harvey S. (1993), "The Carnegie Conjecture: Some Empirical Evidence,” Quarterly Journal of Economics, vol. 108, no. 2 (May), pp. 413-435.

Honig, Marjorie (1998), “Married women's retirement expectations: Do pensions and social security matter?” American Economic Review Papers and Proceedings, vol. 88, no. 2 (May), pp. 202-206.

Horioka, Charles Yuji (2104), “Are Americans and Indians more altruistic than the Japanese and Chinese? Evidence from a new international survey of bequest plans," Review of Economics of the Household, vol. 12, no. 3 (September), pp. 411-437.

Horioka, Charles Yuji; Gahramanov, Emin; Hayat, Aziz; and Tang, Xueli (2018), "Why do children take care of their elderly parents? Are the Japanese any different?” International Economic Review, vol. 59, no. 1 (Feb.), pp. 113-136.

Horioka, Charles Yuji; Kasuga, Norihiro; Yamazaki, Katsuyo; and Watanabe, Wako (1996), "Do the aged dissave in Japan? Evidence from micro Data," Journal of the Japanese and International Economies, vol. 10, no. 3 (Sept.), pp. 295-311.

Horioka, Charles Yuji, and Niimi, Yoko (2017), “Nihon no koureisha setai no chochiku koudou ni kansuru jisshou bunseki (An empirical analysis of the saving behavior of elderly households in Japan),” Keizai Bunseki (Economic Analysis), no. 196 (Dec.), pp. 29-47 (in Japanese).

Hurd, Michael D. (1990), "Research on the Elderly: Economic Status, Retirement, and Consumption and Saving," Journal of Economic Literature, vol. 28, no. 2 (June), pp.565637.

Joulfaian, David, and Wilhelm, Mark O. (1994), “Inheritance and Labor Supply,” Journal of Human Resources, vol. 29, no. 4 (Autumn), pp. 1205-1234. 
Kopczuk, Wojciech (2010), "Economics of estate taxation: A brief review of theory and evidence,” NBER Working Paper No. 15741, National Bureau of Economic Research, Cambridge, MA, USA.

Laferrere, Anne, and Wolff, Francois-Charles (2006), "Microeconomic Models of Family Transfers," in Serge-Christophe Kolm and Jean Mercier Ythier, eds., Handbook of the Economics of Giving, Altruism and Reciprocity, Volume 2 (Amsterdam: Elsevier B.V.), pp. 889-969.

Laitner, John, and Ohlsson, Henry (2001), "Bequest motives: A comparison of Sweden and the United States,” Journal of Public Economics, vol. 79, no. 1 (Jan.), pp. 205-236.

Léonard, Daniel, and Van Long, Ngo (1992), Optimal Control Theory and Static Optimization in Economics. Cambridge, United Kingdom: Cambridge University Press.

Niimi, Yoko, and Horioka, Charles Yuji (2019), “The wealth decumulation behavior of the retired elderly in Japan: The relative importance of precautionary saving and bequest motives” Journal of the Japanese and International Economies, vol. 51 (Mar.), pp. 52-63.

Niizeki, Takeshi, and Hori, Masahiro (2019), “The effect of inheritance receipt on individual labor supply: Evidence from Japanese microdata,” Japan and the World Economy, vol. 49 (Mar.), pp. 176-186.

Patterson, Michael A., and Rao, Anil V. (2014), “GPOPS-II: A MATLAB software for solving multiple-phase optimal control problems using hp-Adaptive Gaussian quadrature collocation methods and sparse nonlinear programming," ACM Transactions on Mathematical Software (TOMS), vol. 41 (Oct.), pp. 1-37.

Rodgers, L. C. G. (2013), Optimal Investment (Springer Briefs in Quantitative Finance). Berlin and Heidelberg: Springer-Verlag (https://www.springer.com/gp/book/9783642352010).

Sugano, Saki, and Matsuyama, Hirokazu (2017), “Isan ga Ko no Keizai Katsudou ni Ataeru Eikyou: Chuukounensha Paneru Deta wo Mochiita Bunseki (The Effect of Bequests on Children: New Evidence from a Panel Data Survey of Elderly People),” Kokumin Keizai Zasshi, vol. 215, no. 1 (January), pp. 35-46 (in Japanese).

Wilhelm, Mark O. (1996), "Bequest behavior and the effect of heirs' earnings: Testing the altruistic model of bequests," American Economic Review, vol. 86, no. 4 (Sept.), pp. 874892.

Wolff, François-Charles (2006), "Parental transfers and the labor supply of children,” Journal of Population Economics, vol. 19, no. 4 (Oct.), pp 853-877. 


\section{Table 1}

Numerical results for the case of strategic or exchange bequest motives

These results correspond to the following parameters of the model. The wage rate $(w)$ is 1 , the age of death $(T+$ $25)$ is 80 , the weight on personal consumption $\left(\varphi_{1}\right)$ is 0.10 , the weight on personal leisure $\left(\varphi_{2}\right)$ is 0.20 , and the care function parameters $z_{1}$ and $z_{2}$ are equal to 0.20 , and 5.00 , respectively.

\begin{tabular}{cccc}
$\begin{array}{c}\text { Strength of exchange } \\
\text { motive }\left(\phi_{3}\right)\end{array}$ & $\begin{array}{c}\text { Age of } \\
\text { retirement }\end{array}$ & $\begin{array}{c}\text { Average number of hours worked } \\
\text { per week }\end{array}$ & $\begin{array}{c}\text { Optimal } \\
\text { bequest }\end{array}$ \\
\hline 0.40 & 60.55 & 40.66 & 5.02 \\
0.50 & 60.10 & 40.77 & 5.33 \\
0.60 & 59.53 & 41.24 & 5.56 \\
0.70 & 59.30 & 41.42 & 5.73 \\
0.80 & 58.93 & 41.84 & 5.88 \\
0.90 & 58.65 & 42.20 & 6.00 \\
\hline
\end{tabular}


Table 2

Summary statistics for the variables used in the estimation model.

This table shows summary statistics for Japanese households based on micro data from the 2012 wave of the Preference Parameters Study (Kurashi no Konomi to Manzokudo nit suite no Chousa) of Osaka University. We used the natural logarithm (log( )) of all continuous variables in the estimation model. Variables and relevant considerations are discussed in section 3.

\begin{tabular}{|c|c|c|c|c|c|c|}
\hline Variable & Mean & Std. dev. & Median & Minimum & Maximum & No. of obs. \\
\hline \multicolumn{7}{|c|}{ Dependent variables } \\
\hline HRSPERWEEK & 41.347 & 15.151 & 40 & 1 & 105 & 1574 \\
\hline log(HRSPERWEEK) & 3.632 & 0.480 & 3.689 & 0 & 4.654 & 1574 \\
\hline RETAGE & 64.694 & 5.402 & 65 & 35 & 90 & 1574 \\
\hline $\log (\mathrm{RETAGE})$ & 4.166 & 0.084 & 4.174 & 3.555 & 4.500 & 1574 \\
\hline FULLTIME & 0.594 & 0.491 & 1 & 0 & 1 & 1574 \\
\hline \multicolumn{7}{|c|}{ Explanatory variables pertaining to bequest motives } \\
\hline BEQMOTALT & 0.294 & 0.456 & 0 & 0 & 1 & 1574 \\
\hline BEQMOTCARE & 0.030 & 0.172 & 0 & 0 & 1 & 1574 \\
\hline BEQMOTFIN & 0.008 & 0.087 & 0 & 0 & 1 & 1574 \\
\hline BEQMOTBUS & 0.008 & 0.091 & 0 & 0 & 1 & 1574 \\
\hline BEQMOTWEAK & 0.473 & 0.499 & 0 & 0 & 1 & 1574 \\
\hline BEQMOTNONE & 0.187 & 0.390 & 0 & 0 & 1 & 1574 \\
\hline \multicolumn{7}{|c|}{ Other explanatory variables } \\
\hline WAGE & 1521.143 & 856.469 & 1296.154 & 346.154 & 6527.473 & 1574 \\
\hline $\log (\mathrm{WAGE})$ & 7.196 & 0.501 & 7.167 & 5.847 & 8.784 & 1574 \\
\hline OTHERINC & 10.045 & 6.628 & 13.5 & 0 & 24.2 & 1574 \\
\hline $\log ($ OTHERINC+1) & 2.053 & 1.004 & 2.674 & 0 & 3.227 & 1574 \\
\hline BEQREC & 0.341 & 0.474 & 0 & 0 & 1 & 1574 \\
\hline BEQEXP & 0.267 & 0.443 & 0 & 0 & 1 & 1574 \\
\hline MALE & 0.571 & 0.495 & 1 & 0 & 1 & 1574 \\
\hline MARRIED & 0.922 & 0.267 & 1 & 0 & 1 & 1574 \\
\hline AGE & 51.230 & 9.852 & 51 & 26 & 79 & 1574 \\
\hline $\log (A G E)$ & 3.917 & 0.199 & 3.932 & 3.258 & 4.369 & 1574 \\
\hline HEALTH & 3.475 & 0.917 & 3 & 1 & 5 & 1574 \\
\hline WORRY & 3.494 & 1.068 & 4 & 1 & 5 & 1574 \\
\hline WORK & 3.576 & 0.858 & 4 & 1 & 5 & 1574 \\
\hline WORKSAT & 3.283 & 0.944 & 3 & 1 & 5 & 1574 \\
\hline SALWKR & 0.838 & 0.369 & 1 & 0 & 1 & 1574 \\
\hline PENSION & 48.221 & 24.424 & 55 & 5 & 95 & 1574 \\
\hline NUMCHILDREN & 2.165 & 0.431 & 2 & 1 & 5 & 1574 \\
\hline GAMBLE & 0.431 & 0.495 & 0 & 0 & 1 & 1574 \\
\hline
\end{tabular}


Table 3

Distribution of work-related outcomes by bequest motive.

This table shows the mean, standard deviation, and the number of observations of the work-related outcomes for each bequest motive. The full sample consists of 1574 observations. We classify BEQMOTALT as an altruistic bequest motive, and BEQMOTCARE, BEQMOTFIN and BEQMOTBUS as strategic or exchange bequest motives as explained in subsection 3.2. FULLTIME is a dummy variable that takes a value of one for respondents who work full-time and a value of zero for respondents who work part-time, HRSPERWEEK is the number of hours the respondent works per week, and RETAGE is the respondent's planned retirement age. See the notes to Table 2 and subsection 3.4 for further details.

\begin{tabular}{|c|c|c|c|c|c|c|c|}
\hline & $\begin{array}{c}\text { Full } \\
\text { sample }\end{array}$ & BEQMOTALT & BEQMOTCARE & BEQMOTFIN & BEQMOTBUS & BEQMOTWEAK & BEQMOTNONE \\
\hline \multicolumn{8}{|c|}{ HRSPERWEEK } \\
\hline Std. dev. & 15.2 & 14.5 & 14.5 & 11.1 & 19.4 & 14.6 & 16.9 \\
\hline \# of obs. & 1574 & 463 & 48 & 12 & 13 & 744 & 294 \\
\hline Std. dev. & 5.4 & 5.5 & 5.3 & 5.8 & 8.5 & 5.5 & 4.9 \\
\hline \# of obs. & 1574 & 463 & 48 & 12 & 13 & 744 & 294 \\
\hline
\end{tabular}




\section{Table 4}

The bequest-work relationship for the number of hours worked per week

The dependent variable is the natural logarithm of the respondent's number of hours worked per week. The bequest motives of interest are the altruistic bequest motive (BEQMOTALT) and the strategic or exchange bequest motive for care (BEQMOTCARE), and the table shows the impact of these variables after controlling for the effect of other bequest motives and explanatory variables on the planned retirement age. The model described in subsection 3.2 is estimated by ordinary least squares and the standard errors are robust to heteroscedasticity. The p-values for the significance of the coefficients are expressed as ${ }^{*} \mathrm{p}<0.1 ; * * \mathrm{p}<0.05$ and ${ }^{* * *} \mathrm{p}<0$. The model's estimates are shown in the eight columns $2-9$ and vary due to variations in the sample, which are based on various combinations of gender, marital status, and/or age. For example, the second column shows the estimates for the full sample, while the third shows the estimates for individuals of both sexes aged 40 years or above.

\begin{tabular}{|c|c|c|c|c|c|c|c|c|}
\hline \multirow[b]{2}{*}{ Explanatory variable } & \multicolumn{8}{|c|}{ Dependent variable: $\log ($ HRSPERWEEK) } \\
\hline & $\begin{array}{l}\text { Both sexes, } \\
\text { all ages }\end{array}$ & $\begin{array}{c}\text { Both sexes, } \\
\text { age }>=40\end{array}$ & $\begin{array}{l}\text { Both sexes, } \\
\text { married, all } \\
\text { ages }\end{array}$ & $\begin{array}{c}\text { Both sexes, } \\
\text { married, } \\
\text { age }>=40\end{array}$ & $\begin{array}{l}\text { Males, } \\
\text { all ages }\end{array}$ & $\begin{array}{l}\text { Males, } \\
\text { age }>=40\end{array}$ & $\begin{array}{l}\text { Married } \\
\text { males, all } \\
\text { ages }\end{array}$ & $\begin{array}{l}\text { Married } \\
\text { males, } \\
\text { age }>=40\end{array}$ \\
\hline \multicolumn{9}{|c|}{ Bequest motives of interest } \\
\hline \multirow[t]{2}{*}{ BEQMOTALT } & $0.053^{*}$ & 0.039 & 0.048 & 0.034 & 0.009 & 0.021 & 0.010 & 0.021 \\
\hline & $(0.031)$ & $(0.034)$ & $(0.031)$ & $(0.035)$ & $(0.027)$ & $(0.029)$ & $(0.027)$ & $(0.030)$ \\
\hline \multirow[t]{2}{*}{ BEQMOTCARE } & $0.121^{* *}$ & $0.099^{*}$ & $0.141^{* * *}$ & $0.121^{* *}$ & $0.096^{* * *}$ & $0.110^{* * *}$ & $0.102^{* * *}$ & $0.117^{* * *}$ \\
\hline & $(0.052)$ & $(0.056)$ & $(0.053)$ & $(0.057)$ & $(0.035)$ & $(0.037)$ & $(0.037)$ & $(0.039)$ \\
\hline \multicolumn{9}{|c|}{ Other bequest motives } \\
\hline \multirow[t]{2}{*}{ BEQMOTFIN } & -0.063 & -0.102 & -0.111 & -0.170 & $-0.240^{* *}$ & $-0.240^{*}$ & $-0.239^{* *}$ & $-0.242^{*}$ \\
\hline & $(0.105)$ & $(0.117)$ & $(0.121)$ & $(0.137)$ & $(0.120)$ & $(0.131)$ & $(0.119)$ & $(0.130)$ \\
\hline \multirow[t]{2}{*}{ BEQMOTBUS } & 0.040 & 0.044 & 0.027 & 0.031 & -0.210 & -0.177 & -0.208 & -0.175 \\
\hline & $(0.173)$ & $(0.169)$ & $(0.175)$ & $(0.171)$ & $(0.246)$ & $(0.240)$ & $(0.247)$ & $(0.240)$ \\
\hline \multirow[t]{2}{*}{ BEQMOTWEAK } & 0.028 & 0.023 & 0.022 & 0.020 & -0.016 & -0.008 & -0.011 & -0.003 \\
\hline & $(0.030)$ & $(0.033)$ & $(0.030)$ & $(0.032)$ & $(0.027)$ & $(0.029)$ & $(0.028)$ & $(0.030)$ \\
\hline \multicolumn{9}{|c|}{ Other explanatory variables } \\
\hline \multirow[t]{2}{*}{$\log (\mathrm{WAGE})$} & $1.097^{*}$ & 0.719 & $1.034^{*}$ & 0.681 & 0.432 & 0.504 & 0.559 & 0.649 \\
\hline & $(0.597)$ & $(0.590)$ & $(0.604)$ & $(0.598)$ & $(0.641)$ & $(0.665)$ & $(0.675)$ & $(0.704)$ \\
\hline \multirow[t]{2}{*}{$\log \left(\mathrm{WAGE}^{2}\right)$} & $-0.081^{* *}$ & -0.055 & $-0.076^{*}$ & -0.052 & -0.036 & -0.041 & -0.045 & -0.051 \\
\hline & $(0.041)$ & $(0.040)$ & $(0.041)$ & $(0.041)$ & $(0.044)$ & $(0.045)$ & $(0.046)$ & $(0.048)$ \\
\hline \multirow[t]{2}{*}{$\log (\mathrm{OTHERINC)}$} & -0.009 & -0.004 & -0.012 & -0.008 & 0.005 & 0.010 & 0.002 & 0.007 \\
\hline & $(0.010)$ & $(0.011)$ & $(0.011)$ & $(0.012)$ & $(0.010)$ & $(0.011)$ & $(0.010)$ & $(0.011)$ \\
\hline \multirow[t]{2}{*}{ BEQREC } & -0.012 & -0.005 & -0.015 & -0.007 & 0.009 & 0.009 & 0.011 & 0.011 \\
\hline & $(0.024)$ & $(0.024)$ & $(0.025)$ & $(0.025)$ & $(0.020)$ & $(0.021)$ & $(0.021)$ & $(0.022)$ \\
\hline \multirow[t]{2}{*}{ BEQEXP } & 0.017 & -0.010 & 0.011 & -0.015 & 0.004 & 0.001 & 0.002 & 0.0005 \\
\hline & $(0.022)$ & $(0.023)$ & $(0.024)$ & $(0.024)$ & $(0.020)$ & $(0.022)$ & $(0.021)$ & $(0.022)$ \\
\hline \multirow[t]{2}{*}{ MALE } & $0.530^{* * *}$ & $0.520^{* * *}$ & $0.536^{* * *}$ & $0.526^{* * *}$ & & & & \\
\hline & $(0.029)$ & $(0.031)$ & $(0.031)$ & $(0.033)$ & & & & \\
\hline \multirow[t]{2}{*}{ MARRIED } & $-0.161^{* * *}$ & $-0.156^{* * *}$ & & & -0.009 & 0.002 & & \\
\hline & $(0.042)$ & $(0.045)$ & & & $(0.044)$ & $(0.046)$ & & \\
\hline \multirow[t]{2}{*}{$\log (A G E)$} & $-0.285^{* * *}$ & $-0.570^{* * *}$ & $-0.270^{* * *}$ & $-0.542^{* * *}$ & $-0.448^{* * *}$ & $-0.672^{* * *}$ & $-0.449^{* * *}$ & $-0.676^{* * *}$ \\
\hline & $(0.065)$ & $(0.086)$ & $(0.067)$ & $(0.088)$ & $(0.054)$ & $(0.079)$ & $(0.055)$ & $(0.080)$ \\
\hline \multirow[t]{2}{*}{ HEALTH } & 0.003 & 0.011 & 0.0003 & 0.009 & 0.009 & 0.008 & 0.010 & 0.009 \\
\hline & $(0.012)$ & $(0.013)$ & $(0.013)$ & $(0.014)$ & $(0.011)$ & (0.013) & $(0.011)$ & $(0.013)$ \\
\hline WORRY & -0.002 & -0.009 & -0.011 & -0.018 & 0.011 & 0.008 & 0.010 & 0.007 \\
\hline
\end{tabular}




\begin{tabular}{lcccccccc} 
& $(0.011)$ & $(0.011)$ & $(0.012)$ & $(0.011)$ & $(0.009)$ & $(0.010)$ & $(0.009)$ & $(0.010)$ \\
WORK & $0.025^{*}$ & $0.028^{* *}$ & 0.021 & $0.024^{*}$ & 0.017 & 0.018 & $0.020^{*}$ & $0.022^{*}$ \\
& $(0.013)$ & $(0.014)$ & $(0.013)$ & $(0.014)$ & $(0.011)$ & $(0.012)$ & $(0.012)$ & $(0.013)$ \\
WORKSAT & -0.019 & -0.020 & -0.014 & -0.015 & 0.005 & 0.011 & 0.002 & 0.009 \\
& $(0.013)$ & $(0.014)$ & $(0.013)$ & $(0.014)$ & $(0.012)$ & $(0.013)$ & $(0.012)$ & $(0.014)$ \\
SALWKR & 0.058 & 0.057 & 0.053 & 0.054 & $0.007^{* * *}$ & -0.005 & 0.010 & -0.002 \\
& $(0.036)$ & $(0.040)$ & $(0.037)$ & $(0.040)$ & $(0.032)$ & $(0.034)$ & $(0.033)$ & $(0.035)$ \\
PENSION & $-0.001^{* * *}$ & $-0.001^{* *}$ & $-0.001^{* * *}$ & $-0.001^{* *}$ & -0.001 & $-0.001^{* *}$ & $-0.001^{* * *}$ & $-0.001^{* *}$ \\
& $(0.0005)$ & $(0.001)$ & $(0.001)$ & $(0.001)$ & $(0.0004)$ & $(0.0005)$ & $(0.0004)$ & $(0.0005)$ \\
NUMCHILDREN & -0.009 & -0.015 & -0.001 & -0.004 & 0.015 & 0.010 & 0.018 & 0.014 \\
& $(0.015)$ & $(0.017)$ & $(0.016)$ & $(0.018)$ & $(0.012)$ & $(0.013)$ & $(0.012)$ & $(0.013)$ \\
GAMBLE & -0.009 & -0.013 & -0.003 & -0.009 & 0.001 & 0.004 & 0.001 & 0.004 \\
& $(0.021)$ & $(0.022)$ & $(0.021)$ & $(0.023)$ & $(0.018)$ & $(0.019)$ & $(0.018)$ & $(0.020)$ \\
Constant & 0.916 & 3.439 & 0.909 & 3.287 & $4.265^{*}$ & $4.901^{* *}$ & 3.781 & $4.366^{*}$ \\
& $(2.209)$ & $(2.174)$ & $(2.251)$ & $(2.233)$ & $(2.369)$ & $(2.483)$ & $(2.502)$ & $(2.640)$ \\
\hline Adjusted R ${ }^{2}$ & 0.283 & 0.283 & 0.292 & 0.290 & 0.161 & 0.177 & 0.163 & 0.179 \\
\# of observations & 1,574 & 1,369 & 1,452 & 1,263 & 899 & 792 & 868 & 763 \\
\hline
\end{tabular}




\section{Table 5}

The bequest-work relationship for the planned retirement age

The dependent variable is the natural logarithm of the respondent's planned retirement age. The bequest motives of interest are the altruistic bequest motive (BEQMOTALT) and the strategic or exchange bequest motive for care (BEQMOTCARE), and the table shows the impact of these variables after controlling for the effect of other bequest motives and explanatory variables on the planned retirement age. The model described in subsection 3.2 is estimated by ordinary least squares and the standard errors are robust to heteroscedasticity. The p-values for the significance of the coefficients are expressed as ${ }^{*} \mathrm{p}<0.1 ;{ }^{* *} \mathrm{p}<0.05$ and ${ }^{* * *} \mathrm{p}<0$. The model's estimates are shown in the eight columns $2-9$ and vary due to variations in the sample, which are based on various combinations of gender, marital status, and/or age. For example, the second column shows the estimates for the full sample, while the third shows the estimates for individuals of both sexes aged 40 years or above.

\begin{tabular}{|c|c|c|c|c|c|c|c|c|}
\hline \multirow[b]{2}{*}{ Explanatory variable } & \multicolumn{8}{|c|}{ Dependent variable: $\log$ (RETAGE) } \\
\hline & $\begin{array}{l}\text { Both } \\
\text { sexes, all } \\
\text { ages }\end{array}$ & $\begin{array}{c}\text { Both } \\
\text { sexes, } \\
\text { age }>=40\end{array}$ & $\begin{array}{c}\text { Both } \\
\text { sexes, } \\
\text { married, } \\
\text { all ages }\end{array}$ & $\begin{array}{c}\text { Both } \\
\text { sexes, } \\
\text { married, } \\
\text { age>=40 }\end{array}$ & $\begin{array}{l}\text { Males, } \\
\text { all ages }\end{array}$ & $\begin{array}{l}\text { Males, } \\
\text { age }>=40\end{array}$ & $\begin{array}{l}\text { Married } \\
\text { males, all } \\
\text { ages }\end{array}$ & $\begin{array}{c}\text { Married } \\
\text { males, } \\
\text { age }>=40\end{array}$ \\
\hline \multicolumn{9}{|c|}{ Bequest motives of interest } \\
\hline BEQMOTALT & $\begin{array}{l}-0.005 \\
(0.005)\end{array}$ & $\begin{array}{l}-0.007 \\
(0.005)\end{array}$ & $\begin{array}{c}-0.006 \\
(0.006)\end{array}$ & $\begin{array}{c}-0.008 \\
(0.006)\end{array}$ & $\begin{array}{c}0.006 \\
(0.007)\end{array}$ & $\begin{array}{l}-0.002 \\
(0.007)\end{array}$ & $\begin{array}{c}0.003 \\
(0.007)\end{array}$ & $\begin{array}{l}-0.005 \\
(0.007)\end{array}$ \\
\hline BEQMOTCARE & $\begin{array}{l}-0.022^{* *} \\
(0.010)\end{array}$ & $\begin{array}{l}-0.022^{* *} \\
(0.010)\end{array}$ & $\begin{array}{l}-0.026^{* *} \\
(0.010)\end{array}$ & $\begin{array}{l}-0.027^{* *} \\
(0.011)\end{array}$ & $\begin{array}{l}-0.017 \\
(0.011)\end{array}$ & $\begin{array}{l}-0.019 \\
(0.012)\end{array}$ & $\begin{array}{l}-0.023^{* *} \\
(0.011)\end{array}$ & $\begin{array}{l}-0.026^{* *} \\
(0.011)\end{array}$ \\
\hline \multicolumn{9}{|c|}{ Other bequest motives } \\
\hline BEQMOTFIN & $\begin{array}{l}-0.044^{* *} \\
(0.021)\end{array}$ & $\begin{array}{l}-0.018 \\
(0.012)\end{array}$ & $\begin{array}{l}-0.050^{* *} \\
(0.024)\end{array}$ & $\begin{array}{l}-0.020 \\
(0.013)\end{array}$ & $\begin{array}{l}-0.026 \\
(0.021)\end{array}$ & $\begin{array}{l}-0.015 \\
(0.016)\end{array}$ & $\begin{array}{l}-0.028 \\
(0.022)\end{array}$ & $\begin{array}{l}-0.016 \\
(0.016)\end{array}$ \\
\hline BEQMOTBUS & $\begin{array}{c}0.012 \\
(0.025)\end{array}$ & $\begin{array}{c}0.006 \\
(0.024)\end{array}$ & $\begin{array}{c}0.011 \\
(0.025)\end{array}$ & $\begin{array}{c}0.006 \\
(0.024)\end{array}$ & $\begin{array}{c}0.037 \\
(0.035)\end{array}$ & $\begin{array}{c}0.028 \\
(0.034)\end{array}$ & $\begin{array}{c}0.035 \\
(0.035)\end{array}$ & $\begin{array}{c}0.027 \\
(0.034)\end{array}$ \\
\hline BEQMOTWEAK & $\begin{array}{l}-0.009^{*} \\
(0.005)\end{array}$ & $\begin{array}{c}-0.013^{* * *} \\
(0.005)\end{array}$ & $\begin{array}{l}-0.009^{*} \\
(0.005)\end{array}$ & $\begin{array}{l}-0.013^{* *} \\
(0.005)\end{array}$ & $\begin{array}{l}-0.001 \\
(0.006)\end{array}$ & $\begin{array}{l}-0.006 \\
(0.006)\end{array}$ & $\begin{array}{l}-0.002 \\
(0.006)\end{array}$ & $\begin{array}{l}-0.007 \\
(0.006)\end{array}$ \\
\hline \multicolumn{9}{|c|}{ Other explanatory variables } \\
\hline $\log ($ WAGE) & $\begin{array}{l}-0.161^{* *} \\
(0.079)\end{array}$ & $\begin{array}{l}-0.153^{*} \\
(0.078)\end{array}$ & $\begin{array}{l}-0.180^{* *} \\
(0.082)\end{array}$ & $\begin{array}{l}-0.169^{* *} \\
(0.083)\end{array}$ & $\begin{array}{c}-0.319^{* * *} \\
(0.109)\end{array}$ & $\begin{array}{c}-0.284^{* * *} \\
(0.108)\end{array}$ & $\begin{array}{c}-0.366^{* * *} \\
(0.107)\end{array}$ & $\begin{array}{c}-0.338^{* * *} \\
(0.106)\end{array}$ \\
\hline $\log \left(\mathrm{WAGE}^{2}\right)$ & $\begin{array}{l}0.010^{*} \\
(0.005)\end{array}$ & $\begin{array}{l}0.010^{*} \\
(0.005)\end{array}$ & $\begin{array}{l}0.012^{* *} \\
(0.006)\end{array}$ & $\begin{array}{l}0.011^{*} \\
(0.006)\end{array}$ & $\begin{array}{l}0.020^{* * *} \\
(0.007)\end{array}$ & $\begin{array}{l}0.018^{* *} \\
(0.007)\end{array}$ & $\begin{array}{l}0.024^{* * *} \\
(0.007)\end{array}$ & $\begin{array}{l}0.022^{* * *} \\
(0.007)\end{array}$ \\
\hline $\log ($ OTHERINC) & $\begin{array}{l}-0.004^{* *} \\
(0.002)\end{array}$ & $\begin{array}{l}-0.003^{*} \\
(0.002)\end{array}$ & $\begin{array}{l}-0.001 \\
(0.002)\end{array}$ & $\begin{array}{l}-0.002 \\
(0.002)\end{array}$ & $\begin{array}{c}0.002 \\
(0.002)\end{array}$ & $\begin{array}{c}0.002 \\
(0.002)\end{array}$ & $\begin{array}{c}0.002 \\
(0.002)\end{array}$ & $\begin{array}{c}0.002 \\
(0.002)\end{array}$ \\
\hline BEQREC & $\begin{array}{c}0.002 \\
(0.004)\end{array}$ & $\begin{array}{c}0.003 \\
(0.004)\end{array}$ & $\begin{array}{c}0.004 \\
(0.004)\end{array}$ & $\begin{array}{c}0.005 \\
(0.004)\end{array}$ & $\begin{array}{l}-0.003 \\
(0.005)\end{array}$ & $\begin{array}{l}-0.002 \\
(0.005)\end{array}$ & $\begin{array}{l}-0.002 \\
(0.005)\end{array}$ & $\begin{array}{l}-0.0002 \\
(0.005)\end{array}$ \\
\hline BEQEXP & $\begin{array}{c}-0.013^{* * *} \\
(0.004)\end{array}$ & $\begin{array}{c}-0.012^{* * *} \\
(0.005)\end{array}$ & $\begin{array}{c}-0.014^{* * *} \\
(0.004)\end{array}$ & $\begin{array}{c}-0.013^{* * *} \\
(0.005)\end{array}$ & $\begin{array}{l}-0.009^{*} \\
(0.005)\end{array}$ & $\begin{array}{l}-0.007 \\
(0.005)\end{array}$ & $\begin{array}{l}-0.010^{* *} \\
(0.005)\end{array}$ & $\begin{array}{l}-0.008 \\
(0.005)\end{array}$ \\
\hline MALE & $\begin{array}{c}0.049^{* * *} \\
(0.004)\end{array}$ & $\begin{array}{l}0.046^{* * *} \\
(0.004)\end{array}$ & $\begin{array}{l}0.052^{* * *} \\
(0.004)\end{array}$ & $\begin{array}{l}0.049^{* * *} \\
(0.004)\end{array}$ & & & & \\
\hline MARRIED & $\begin{array}{c}-0.030^{* * *} \\
(0.007)\end{array}$ & $\begin{array}{c}-0.022^{* * *} \\
(0.007)\end{array}$ & & & $\begin{array}{l}-0.006 \\
(0.015)\end{array}$ & $\begin{array}{l}-0.004 \\
(0.016)\end{array}$ & & \\
\hline $\log (\mathrm{AGE})$ & $\begin{array}{l}0.119^{* * *} \\
(0.012)\end{array}$ & $\begin{array}{l}0.163^{* * *} \\
(0.013)\end{array}$ & $\begin{array}{l}0.121^{* * *} \\
(0.012)\end{array}$ & $\begin{array}{l}0.159^{* * *} \\
(0.014)\end{array}$ & $\begin{array}{l}0.111^{* * *} \\
(0.013)\end{array}$ & $\begin{array}{l}0.140^{* * *} \\
(0.016)\end{array}$ & $\begin{array}{l}0.113^{* * *} \\
(0.014)\end{array}$ & $\begin{array}{l}0.140^{* * *} \\
(0.016)\end{array}$ \\
\hline HEALTH & $\begin{array}{c}0.003 \\
(0.002)\end{array}$ & $\begin{array}{c}0.003 \\
(0.002)\end{array}$ & $\begin{array}{c}0.003 \\
(0.002)\end{array}$ & $\begin{array}{l}0.004^{*} \\
(0.002)\end{array}$ & $\begin{array}{l}0.004^{*} \\
(0.002)\end{array}$ & $\begin{array}{l}0.005^{*} \\
(0.003)\end{array}$ & $\begin{array}{l}0.005^{* *} \\
(0.003)\end{array}$ & $\begin{array}{l}0.005^{* *} \\
(0.003)\end{array}$ \\
\hline
\end{tabular}




\begin{tabular}{lcccccccc} 
WORRY & -0.0001 & -0.002 & 0.0005 & -0.001 & -0.0002 & -0.002 & -0.0002 & -0.002 \\
& $(0.002)$ & $(0.002)$ & $(0.002)$ & $(0.002)$ & $(0.002)$ & $(0.002)$ & $(0.002)$ & $(0.002)$ \\
WORK & $0.010^{* * *}$ & $0.010^{* * *}$ & $0.010^{* * *}$ & $0.010^{* * *}$ & $0.006^{* *}$ & $0.007^{* *}$ & $0.005^{*}$ & $0.005^{*}$ \\
& $(0.003)$ & $(0.003)$ & $(0.003)$ & $(0.003)$ & $(0.003)$ & $(0.003)$ & $(0.003)$ & $(0.003)$ \\
WORKSAT & $0.004^{* *}$ & $0.004^{* *}$ & $0.004^{*}$ & $0.004^{*}$ & 0.003 & $0.004^{*}$ & 0.003 & $0.005^{*}$ \\
& $(0.002)$ & $(0.002)$ & $(0.002)$ & $(0.002)$ & $(0.003)$ & $(0.003)$ & $(0.003)$ & $(0.003)$ \\
SALWKR & $-0.067^{* * *}$ & $-0.067^{* * *}$ & $-0.068^{* * *}$ & $-0.069^{* * *}$ & $-0.070^{* * *}$ & $-0.073^{* * *}$ & $-0.071^{* * *}$ & $-0.075^{* * *}$ \\
& $(0.005)$ & $(0.005)$ & $(0.006)$ & $(0.006)$ & $(0.007)$ & $(0.007)$ & $(0.007)$ & $(0.007)$ \\
PENSION & $-0.0003^{* * *}$ & $-0.0003^{* * *}$ & $-0.0003^{* * *}$ & $-0.0003^{* * *}$ & -0.0002 & $-0.0002^{*}$ & -0.0002 & $-0.0002^{*}$ \\
& $(0.0001)$ & $(0.0001)$ & $(0.0001)$ & $(0.0001)$ & $(0.0001)$ & $(0.0001)$ & $(0.0001)$ & $(0.0001)$ \\
NUMCHILDREN & 0.001 & 0.0005 & 0.001 & -0.0005 & 0.003 & 0.001 & 0.002 & -0.001 \\
\multirow{2}{*}{ GAMBLE } & $(0.003)$ & $(0.003)$ & $(0.003)$ & $(0.003)$ & $(0.003)$ & $(0.004)$ & $(0.003)$ & $(0.003)$ \\
& -0.0003 & -0.001 & -0.001 & -0.001 & -0.004 & -0.006 & -0.002 & -0.004 \\
Constant & $(0.004)$ & $(0.004)$ & $(0.004)$ & $(0.004)$ & $(0.004)$ & $(0.004)$ & $(0.004)$ & $(0.004)$ \\
& $4.339^{* * *}$ & $4.131^{* * *}$ & $4.362^{* * *}$ & $4.182^{* * *}$ & $5.003^{* * *}$ & $4.764^{* * *}$ & $5.172^{* * *}$ & $4.971^{* * *}$ \\
\hline Adjusted R & $(0.299)$ & $(0.295)$ & $(0.311)$ & $(0.314)$ & $(0.415)$ & $(0.417)$ & $(0.405)$ & $(0.410)$ \\
\hline
\end{tabular}




\section{Table 6}

The bequest-work relationship for employment status (full-time vs. part-time)

The dependent variable is an indicator variable for whether or not the respondent works full-time. The bequest motives of interest are the altruistic bequest motive (BEQMOTALT) and the strategic or exchange bequest motive for care (BEQMOTCARE), and the table shows the impact of these variables after controlling for the effect of other bequest motives and explanatory variables on the planned retirement age. The model described in subsection 3.2 is estimated by the probit method, the coefficients and the p-values are for (average) marginal effects, and the standard errors are robust to heteroscedasticity. The $\mathrm{p}$-values for the significance of the coefficients are expressed as $* \mathrm{p}<0.1 ; * * \mathrm{p}<0.05$ and ${ }^{* * *} \mathrm{p}<0$. The model's estimates are shown in the eight columns $2-9$ and vary due to variations in the sample, which are based on various combinations of gender, marital status, and/or age. For example, the second column shows the estimates for the full sample, while the third shows the estimates for individuals of both sexes aged 40 years or above.

Dependent variable: FULLTIME (full-time dummy)

$\begin{array}{cccccccc}\text { Explanatory variable } & \begin{array}{c}\text { Both } \\ \text { sexes, all } \\ \text { ages }\end{array} & \begin{array}{c}\text { Both sexes, } \\ \text { age }>=40\end{array} & \begin{array}{c}\text { Both sexes, } \\ \text { married, all } \\ \text { ages }\end{array} & \begin{array}{c}\text { Both sexes, } \\ \text { married, } \\ \text { age }>=40\end{array} & \begin{array}{c}\text { Males, } \\ \text { all ages }\end{array} & \begin{array}{c}\text { Males, } \\ \text { age }>=40\end{array} & \begin{array}{c}\text { Married } \\ \text { males, all } \\ \text { ages }\end{array} \text { ages }>=40\end{array}$

\begin{tabular}{|c|c|c|c|c|c|c|c|c|}
\hline \multicolumn{9}{|c|}{ Bequest motives of interest } \\
\hline \multirow[t]{2}{*}{ BEQMOTALT } & $0.082^{* *}$ & 0.021 & $0.079^{*}$ & 0.013 & $0.060^{*}$ & 0.021 & $0.061^{*}$ & 0.024 \\
\hline & $(0.039)$ & $(0.044)$ & $(0.042)$ & $(0.046)$ & $(0.035)$ & $(0.041)$ & $(0.035)$ & $(0.040)$ \\
\hline \multirow[t]{2}{*}{ BEQMOTCARE } & $0.141^{*}$ & 0.078 & $0.146^{* *}$ & 0.076 & $0.133^{* * *}$ & $0.131^{*}$ & $0.128^{* * *}$ & $0.126^{*}$ \\
\hline & $(0.074)$ & $(0.088)$ & $(0.073)$ & $(0.089)$ & $(0.050)$ & $(0.071)$ & $(0.048)$ & $(0.069)$ \\
\hline \multicolumn{9}{|c|}{ Other bequest motives } \\
\hline \multirow[t]{2}{*}{ BEQMOTFIN } & -0.224 & $-0.310^{* *}$ & $-0.375^{* *}$ & $-0.488^{* * *}$ & $-0.385^{* *}$ & $-0.527^{* * *}$ & $-0.369^{* *}$ & $-0.511^{* * *}$ \\
\hline & $(0.159)$ & $(0.154)$ & $(0.149)$ & $(0.111)$ & $(0.167)$ & $(0.164)$ & $(0.176)$ & $(0.179)$ \\
\hline \multirow[t]{2}{*}{ BEQMOTBUS } & 0.134 & 0.102 & 0.134 & 0.104 & -0.062 & -0.071 & -0.053 & -0.056 \\
\hline & $(0.184)$ & $(0.185)$ & $(0.189)$ & $(0.190)$ & $(0.118)$ & $(0.124)$ & $(0.113)$ & $(0.116)$ \\
\hline \multirow[t]{2}{*}{ BEQMOTWEAK } & 0.033 & -0.008 & 0.039 & -0.003 & 0.022 & -0.001 & 0.035 & 0.015 \\
\hline & $(0.038)$ & $(0.041)$ & $(0.040)$ & $(0.044)$ & $(0.036)$ & $(0.041)$ & $(0.036)$ & $(0.041)$ \\
\hline \multicolumn{9}{|c|}{ Other explanatory variables } \\
\hline \multirow[t]{2}{*}{$\log (\mathrm{WAGE})$} & 1.112 & 1.088 & 1.14 & 1.152 & 0.436 & 0.557 & 0.314 & 0.400 \\
\hline & (1.157) & (1.195) & $(1.358)$ & $(1.386)$ & $(0.979)$ & $(1.065)$ & $(0.993)$ & (1.055) \\
\hline \multirow[t]{2}{*}{$\log \left(\mathrm{WAGE}^{2}\right)$} & -0.054 & -0.052 & -0.055 & -0.056 & -0.019 & -0.027 & -0.011 & -0.017 \\
\hline & $(0.079)$ & $(0.081)$ & $(0.093)$ & $(0.095)$ & $(0.066)$ & $(0.072)$ & $(0.067)$ & $(0.071)$ \\
\hline \multirow[t]{2}{*}{$\log (\mathrm{OTHERINC})$} & -0.018 & -0.019 & -0.021 & -0.026 & 0.012 & 0.011 & 0.013 & 0.013 \\
\hline & $(0.015)$ & $(0.016)$ & $(0.016)$ & $(0.017)$ & $(0.013)$ & $(0.014)$ & $(0.013)$ & $(0.014)$ \\
\hline \multirow[t]{2}{*}{ BEQREC } & 0.002 & 0.023 & 0.009 & 0.036 & 0.002 & 0.033 & -0.001 & 0.033 \\
\hline & $(0.031)$ & $(0.033)$ & $(0.033)$ & $(0.034)$ & $(0.029)$ & $(0.030)$ & $(0.029)$ & $(0.03)$ \\
\hline \multirow[t]{2}{*}{ BEQEXP } & $0.072^{* *}$ & 0.049 & $0.063^{*}$ & 0.033 & $0.062^{* *}$ & $0.064^{*}$ & $0.058^{* *}$ & $0.057^{*}$ \\
\hline & $(0.032)$ & $(0.035)$ & $(0.034)$ & $(0.036)$ & $(0.029)$ & $(0.033)$ & $(0.029)$ & $(0.033)$ \\
\hline \multirow[t]{2}{*}{ MALE } & $0.351^{* * *}$ & $0.337^{* * *}$ & $0.377^{* * *}$ & $0.369^{* * *}$ & & & & \\
\hline & $(0.030)$ & $(0.033)$ & $(0.031)$ & $(0.034)$ & & & & \\
\hline \multirow[t]{2}{*}{ MARRIED } & $-0.142^{* * *}$ & $-0.142^{* *}$ & & & $0.166^{*}$ & $0.228^{* *}$ & & \\
\hline & $(0.053)$ & $(0.058)$ & & & $(0.088)$ & (0.099) & & \\
\hline \multirow[t]{2}{*}{$\log (A G E)$} & $-0.483^{* * *}$ & $-0.780^{* * *}$ & $-0.496^{* * *}$ & $-0.825^{* * *}$ & $-0.590^{* * *}$ & $-0.881^{* * *}$ & $-0.559^{* * *}$ & $-0.859^{* * *}$ \\
\hline & $(0.086)$ & $(0.121)$ & $(0.092)$ & $(0.131)$ & $(0.099)$ & $(0.132)$ & $(0.098)$ & $(0.131)$ \\
\hline \multirow[t]{2}{*}{ HEALTH } & 0.006 & 0.001 & -0.002 & -0.007 & 0.021 & 0.013 & 0.017 & 0.009 \\
\hline & $(0.016)$ & $(0.017)$ & $(0.017)$ & $(0.018)$ & $(0.015)$ & $(0.018)$ & $(0.015)$ & $(0.018)$ \\
\hline
\end{tabular}




\begin{tabular}{|c|c|c|c|c|c|c|c|c|}
\hline \multirow[t]{2}{*}{ WORRY } & 0.0003 & -0.013 & -0.013 & $-0.029^{*}$ & 0.017 & 0.006 & 0.011 & -0.001 \\
\hline & $(0.014)$ & $(0.015)$ & $(0.015)$ & $(0.016)$ & $(0.014)$ & $(0.015)$ & $(0.014)$ & $(0.015)$ \\
\hline \multirow[t]{2}{*}{ WORK } & -0.008 & -0.013 & -0.019 & -0.024 & -0.013 & -0.014 & -0.018 & -0.020 \\
\hline & $(0.018)$ & $(0.019)$ & $(0.019)$ & $(0.021)$ & $(0.018)$ & $(0.020)$ & $(0.018)$ & $(0.020)$ \\
\hline \multirow[t]{2}{*}{ WORKSAT } & -0.023 & -0.004 & -0.019 & -0.003 & -0.001 & 0.011 & -0.003 & 0.010 \\
\hline & $(0.017)$ & $(0.018)$ & $(0.018)$ & $(0.019)$ & $(0.017)$ & $(0.019)$ & $(0.017)$ & $(0.019)$ \\
\hline \multirow[t]{2}{*}{ SALWKR } & $0.251^{* * *}$ & $0.237^{* * *}$ & $0.253^{* * *}$ & $0.232^{* * *}$ & $0.345^{* * *}$ & $0.300^{* * *}$ & $0.353^{* * *}$ & $0.305^{* * *}$ \\
\hline & $(0.048)$ & $(0.050)$ & $(0.052)$ & $(0.053)$ & $(0.061)$ & $(0.062)$ & $(0.062)$ & $(0.064)$ \\
\hline \multirow[t]{2}{*}{ PENSION } & 0.0001 & 0.0001 & -0.0002 & 0.000 & -0.0004 & 0.0002 & -0.001 & -0.0001 \\
\hline & $(0.001)$ & $(0.001)$ & $(0.001)$ & $(0.001)$ & $(0.001)$ & $(0.001)$ & $(0.001)$ & $(0.001)$ \\
\hline \multirow[t]{2}{*}{ NUMCHILDREN } & $0.045^{* *}$ & $0.051^{* *}$ & $0.041^{*}$ & $0.048^{*}$ & $0.043^{*}$ & $0.047^{*}$ & 0.037 & 0.038 \\
\hline & $(0.021)$ & $(0.024)$ & $(0.023)$ & $(0.026)$ & $(0.023)$ & $(0.027)$ & $(0.023)$ & $(0.026)$ \\
\hline \multirow[t]{2}{*}{ GAMBLE } & $0.047^{*}$ & $0.055^{*}$ & $0.057^{*}$ & $0.065^{* *}$ & 0.025 & 0.029 & 0.035 & 0.041 \\
\hline & $(0.029)$ & $(0.03)$ & $(0.030)$ & $(0.032)$ & $(0.027)$ & $(0.03)$ & $(0.027)$ & $(0.03)$ \\
\hline $\begin{array}{l}\text { Correctly predicted } \\
\text { (\%) }\end{array}$ & 77.26 & 76.77 & 77.9 & 70.99 & 82.31 & 82.2 & 81.44 & 70.99 \\
\hline McFadden $\mathrm{R}^{2}$ & 0.27 & 0.27 & 0.29 & 0.15 & 0.28 & 0.29 & 0.31 & 0.15 \\
\hline \# of observations & 1,574 & 1,369 & 1,452 & 1,263 & 899 & 792 & 868 & 763 \\
\hline
\end{tabular}

